\title{
Speech Error Elicitation and Co-occurrence Restrictions in Two Ethiopian Semitic Languages
}

\author{
Sharon Rose', Lisa King ${ }^{2}$ \\ ${ }^{1}$ University of California, San Diego \\ ${ }^{2}$ University of Maryland, College Park
}

\section{Key words}

co-occurrence restrictions

Ethiopian Semitic

similarity

speech errors

\section{Abstract}

This article reports the results of speech error elicitation experiments investigating the role of two consonant co-occurrence restrictions in the productive grammar of speakers of two Ethiopian Semitic languages, Amharic and Chaha. Higher error rates were found with consonant combinations that violated co-occurrence constraints than with those that had only a high degree of shared phonological similarity or low frequency of co-occurrence. Sequences that violated two constraints had the highest error rates. The results indicate that violations of consonant co-occurrence restrictions significantly increase error rates in the productions of native speakers, thereby supporting the psychological reality of the constraints.

\section{Introduction}

Speech error research is predicated on the assumption that slips of the tongue are constrained by the phonological system of the language, thereby providing an important source of external evidence for phonological structure and specification. Several factors have been reported to influence rate and type of errors, based on results drawn from naturally occurring slips of the tongue and experimentally-induced speech errors, as well as from normal and aphasic speech (Béland \& Favreau, 1991; Blumstein, 1973; Gordon, 2002; Kohn, Melvold, \& Smith, 1995; Romani \& Calabrese, 1998, among others) These factors include similarity of sounds, frequency effects (of sounds or words), markedness or underspecification, and position in the word or syllable.

Acknowledgments: This research was presented at the MIT Markedness and the Lexicon Workshop and a UCLA Psycholinguistics Colloquium, in 2003. We thank those audiences, in particular Matt Goldrick, Carson Schütze, Donca Steriade, Rachel Walker, and Colin Wilson. We are indebted to Mark Appelbaum and Shannon Casey for advice on statistical methods and experimental design. We gratefully acknowledge Tensay Tesfamariam, Tadesse Sefer, and Woldemanuel Habtemariam for assistance in conducting these experiments in Ethiopia. Finally, we thank the reviewers and editors for their extremely helpful comments and suggestions for improving the paper. This project was supported by a UCSD Academic Senate Grant and a Hellman Fellowship awarded to the first author.

Address for correspondence. Sharon Rose, Department of Linguistics 0108, University of California, San Diego, 9500 Gilman Drive, La Jolla, CA 92093-0108; e-mail: <rose@ling.ucsd.edu>. 
Co-occurrence restrictions, the subject of this paper, have not been reported to induce greater error rates.

Increased similarity between consonants correlates with increased susceptibility to speech errors, whether natural or induced (Abd-El-Jawad \& Abu-Salim, 1987; Berg, 1991; van den Broecke \& Goldstein, 1980; Fromkin, 1971; García-Albea, del Viso, \& Igoa, 1989; Levitt \& Healy, 1985; MacKay, 1970; Nooteboom, 1967; Shattuck-Hufnagel \& Klatt, 1979; Stemberger, 1991b; Walker, 2007; Wilshire, 1999). Wilshire (1999) used a tongue twister paradigm with real words to elicit speech errors. A tongue twister paradigm involves a reading or repetition task in which subjects are asked to produce words or syllables which alternate in a variety of ways, similar to a tongue twister (Frisch, 2000; Kupin, 1982; MacKay, 1970; Schwartz, Saffran, Bloch, \& Dell, 1994; Shattuck-Huffnagel, 1992, among others). Wilshire's results showed that more errors were evident for highly similar phoneme pairs than for less similar pairs.

Walker (2007) and Walker, Hacopian and Taki (2002) used the SLIPS technique (Baars, Motley \& MacKay, 1975; Dell, 1990; Levitt \& Healey, 1985; Motley \& Baars, 1975; Stemberger, 1991b, among many others) to elicit speech errors. The SLIPS technique uses priming by presenting subjects with several pairs of real or novel words with similar initial sounds followed by a critical cue pair of words with the same initial sounds switched. Subjects are asked to read the cue pair, which, due to the influence of the first few pairs, often results in speech errors. The aim of Walker's experiment was to discover whether similar pairs of consonants (nasal-voiced stop) would induce more errors than nonsimilar (nasal-voiceless stop). The results confirmed more errors with similar pairs than nonsimilar pairs. Spreading-activation models of speech errors suggest that speakers form connections between similar speech sounds through shared features, and this activation can result in production problems whereby a target segment will be replaced by a similar segment (Dell, 1984; Dell \& Reich, 1980; Frisch, 2004; MacKay, 1970, 1987; McClelland \& Rumelhart, 1981; Stemberger, 1982, 1985a,b).

Similarity is typically calculated by counting shared distinctive features. Two recent methods of counting shared features are the SpMV model (Bailey \& Hahn, 2005) and the shared feature class model (SFC) (Frisch, Pierrehumbert, \& Broe, 2004). Bailey and Hahn (2005) propose a similarity metric (SPMV) which calculates the number of features shared by two consonant phonemes within the dimensions of place, sonorant-obstruent, manner and voicing (see also Kohn et al., 1995, for a similar approach). Features are unary, rather than binary distinctive features. Place features are (labial, dental, alveolar, palatal, velar, and glottal), manner features are (stop, fricative, affricate, nasal, glide, lateral, rhotic). Sonorant-obstruent has two choices (sonorant, obstruent) as does voice (voiceless, voiced). A similarity ranking from 1-4 is based on featural differences, such that ' 1 ' signifies high similarity and '4' signifies low. Frisch, Pierrehumbert and Broe (2004) use the shared feature classes (SFC) method (Frisch, 1996, 2000), based on a calculation of shared feature classes divided by [shared feature classes + nonshared feature classes]. Shared features are calculated using standard binary distinctive features. This calculation returns similarity rates for individual consonant combinations and takes the phoneme inventory of a language into account in assessing similarity, since the number of shared feature classes will depend on the number of phonemes and the features involved. In the 
experiments reported in the paper, both these methods of calculating similarity will be assessed and compared with another method based on shared place and manner features (SIM-PM).

The role of frequency in influencing speech errors is less straightforward. Frequency can refer to different levels of linguistic description, such as frequency of particular sounds in the language, syllable frequency or frequency of co-occurrence. Shattuck-Hufnagel and Klatt (1979) and Stemberger (1991b), in studies of naturally occurring errors, found that some high frequency sounds such as /s/ are more likely to be replaced (act as targets) by low frequency sounds such as $/ \mathrm{J} /$ (act as intrusions). Shattuck-Hufnagel and Klatt (1979) found no other frequency bias. In a tongue twister paradigm, Levitt and Healey (1985) elicited speech errors in two tongue twister nonsense syllable experiments in English using coronal sounds: /s $\int \mathrm{t} f \mathrm{t} \theta$ /. They found that infrequent segments tend to serve as targets whereas frequent segments tend to serve as intrusions. Blumstein (1973) also reports a negative correlation between phoneme frequency and error rates in the speech of aphasic individuals. Stemberger (1991b) reports some cases of low frequency phonemes being replaced by high frequency phonemes, but the reverse was also found. Stemberger $(1991 \mathrm{a}, \mathrm{b})$ attributes the highfrequency error rates to "anti-frequency effects" due to underspecification. If coronals are underspecified for place of articulation, other segments' place specifications will intrude more easily. Paradoxically, both high frequency (Kean, 1975) and underspecification (Archangeli, 1984) are correlated with unmarked status. Underspecification has been used to explain speech error patterns where frequency does not play a role or, as above, is contradictory to expectations. Béland and Favreau (1991) observe a higher incidence of substitutions of coronals (taking consonant frequency into account) in elicited real word aphasic speech errors. They attribute this pattern to underspecification of coronals. Kohn et al. (1995), in a study of aphasic speech, report that voiceless target consonants are substituted by voiced consonants in the presence of a contextual trigger, but no such effect is found with voiceless substituting for voiced, or for place of articulation. Their conclusion is that markedness and underspecification play a role in voice assimilation (termed 'harmony'). As markedness correlates with frequency, this could be construed as an anti-frequency effect in which high frequency (voiceless) phonemes were replaced by low-frequency (voiced) phonemes.

In the aforementioned studies, frequency is calculated individually for each consonant. Studies which focus on frequency of co-occurrence typically refer to permissible syllable constituents (e.g., onset sequences in Moreton, 2004) or positions in the word (word-initial position in Frisch, 2000; Shattuck-Huffnagel, 1988). Other psycholinguistic research has shown that high-probability phonotactics are easier to process than low-probability phonotactics (Vitevitch \& Luce, 1999; Vitevitch, Luce, Charles-Luce, \& Kemmerer, 1997), but it is not clear how this influences speech errors. Thus, the evidence for frequency effects on speech errors is inconclusive.

Numerous languages show evidence of co-occurrence constraints on combinations of vowels or consonants. Although many such constraints may be expressed in terms of syllables (e.g., permissible onsets), constraints are also imposed on noncontiguous speech segments, disallowing two consonants of a particular class within a word or morpheme. These constraints often take the form of inducing "harmonic" patterns, in which consonants must match for a particular feature. For example, in Aari, an 
Omotic language of Ethiopia (Hayward, 1990), a co-occurrence constraint prohibits a combination of alveolar and palatoalveolar fricatives within the word. Coronal fricatives within roots must match, and suffixes assimilate to the root fricative: for example, duk-sis 'cause to bury' versus faan-fif 'cause to urinate'.

In other languages, constraints on consonants may be dissimilatory in nature. For example, in Imdlawn Tashlhiyt Berber (Elmedlaoui, 1995), roots may not contain two labial consonants. When the reciprocal labial prefix $/ \mathrm{m}-/$ associates to a root with a labial consonant, it dissimilates to [n]: $m$ - $\hbar$ asad 'envy' versus $n$-baddal 'change' (Elmedlaoui, 1995, pp.74-77): See also McCarthy (1986, 1988), Yip (1988, 1989), MacEachern (1997 [1999]), and Suzuki (1998) on typological dissimilation. While on the face of it, dissimilatory and harmonic constraints appear to be contradictory, they are united under a basic principle, that similar but nonidentical consonants are dispreferred. Such consonants are either rendered more similar or identical (harmony) or less similar (disharmony).

Two recent typological studies of long-distance harmonic or agreement constraints (Hansson, 2001b; Rose \& Walker, 2004) point to two striking parallel properties between consonant harmony and speech errors. The first is the high degree of similarity parallel between consonant harmony and speech processing (Hansson, 2001a,b). Hansson observes that the "palatal bias" effect found mainly in anticipatory speech errors (Shattuck-Hufnagel \& Klatt, 1979; Stemberger, 1991a), in which high frequency sounds such as /s/ are more likely to be replaced by low frequency / $/$ sounds, is found in coronal harmony systems, which also tend to be anticipatory and involve similar alveolar/palatal restrictions. Hansson (2001a,b) and Rose and Walker (2004) hypothesize that avoidance of sound combinations which present production or processing difficulties, such as those attested in speech errors, may become entrenched as grammatical constraints on consonant co-occurrence at a distance. Psycholinguistic evidence indeed suggests that speakers are sensitive to such co-occurrence constraints in wordlikeness judgment tasks (Frisch \& Zawaydeh, 2001), and speech perception experiments (Moreton, 2004). The consensus from these studies is that co-occurrence constraints are encoded in speakers' phonological grammar. In terms of speech error studies, it is reported that speech errors rarely result in the production of sequences that violate phonotactic constraints (Abd-El-Jawad \& Abu-Salim, 1987; Goldrick, 2004; MacKay, 1972; Vousden, Brown, \& Harley, 2000), and some studies are designed explicitly to address this question (Dell, Reed, Adams, \& Meyer, 2000). Yet, none of these studies focuses on whether illicit sequences will engender more errors than licit sequences, which is the goal of the current study.

Given that similarity has been observed to induce speech errors and that co-occurrence constraints are grounded in similarity, the question arises as to whether the presence of a co-occurrence constraint in the grammar will lead to more speech errors when compared to consonant combinations with a high degrees of similarity but no observable constraint. Our research questions are as follows: (i) do consonant combinations which violate long distance phonological co-occurrence constraints on similar consonants result in more speech errors than similar sequences that are not subject to co-occurrence constraints? ${ }^{1}$ (ii) will high similarity between consonant

1 The term 'phonotactic constraint' or 'co-occurrence constraint' can be used to refer to constraints 
combinations which do not violate a co-occurrence constraint still exhibit an increase of errors in speakers' productions in relation to low similarity combinations? and (iii) will consonant combinations with a low co-occurrence frequency but not subject to a co-occurrence constraint lead to an increase in errors in relation to high frequency combinations? This study addresses these questions through an investigation of co-occurrence constraints on consonants in the lexical verb roots of two related South Ethiopian Semitic languages, Amharic and Chaha, which are not mutually intelligible. The main hypothesis is that consonant combinations subject to co-occurrence constraints will trigger higher error rates than consonant combinations not known to violate co-occurrence constraints, when similarity and frequency are controlled.

\section{Co-occurrence constraints in Amharic and Chaha}

Semitic languages are known for consonant co-occurrence constraints on their lexical roots, typically composed of three consonants. One of the co-occurrence constraints found in the two Ethiopian Semitic languages under investigation, Chaha and Amharic, is the place of articulation constraint (POAC). This constraint bans roots with two or more consonants drawn from the same place of articulation (labial, coronal, dorsal, guttural). The coronal class is usually subdivided into a class of coronal sonorants and coronal obstruents. This is a dissimilatory-type constraint, and a pan-Semitic pattern documented for Arabic (Bachra, 2001; Cantineau, 1946; Elmedlaoui, 1995; Frisch, Pierrehumbert, \& Broe, 2004; Frisch \& Zawaydeh, 2000; Greenberg, 1950; Kurylowicz, 1972; McCarthy, 1988, 1994; Pierrehumbert, 1993; Yip, 1988), Akkadian (Reiner, 1966), Hebrew (Bachra, 2001; Koskinen, 1964; Kurylowicz, 1972; Tobin, 1990; Weitzman, 1987), Amharic (Bender \& Fulass, 1978) and Tigrinya (Buckley, 1997). It is also found in other Afro-Asiatic languages such as Afar (Hayward \& Hayward, 1989) and Berber (Elmedlaoui, 1995), as well as in Javanese (Mester, 1986), Russian (Padgett, 1995), Muna (Pater \& Coetzee, 2005), Japanese (Kawahara, Ono, \& Sudo, 2005) and English (Berkley, 1994, 2000). This constraint is often referred to by the name "Obligatory Contour Principle" (OCP), a general phonological principle originally proposed by Leben (1973) for tone, but since extended to include any identical phonological features or segments.

The other co-occurrence constraint found in Chaha and Amharic is a "Laryngeal constraint" (LC), and was described for Chaha in Leslau (1979), Banksira (2000), O'Bryan and Rose (2001), and Rose and Walker (2004). It takes the form of a harmony constraint, and applies only between coronal and velar stops, as labials show no contrast for laryngeal features. ${ }^{2}$ It states that a verb root may not contain two contrasting oral stops with different laryngeal features. Chaha and Amharic have a three-way

on the occurrence of particular sounds in specific positions, such as "no syllable-initial [n]" in English, or "no syllable initial [tl] or [dl]" sequences. The focus in this discussion is on co-occurrence constraints on consonants regardless of syllable or word position.

2 In both languages, the labial stops [p] and [p'] occur in borrowed words. In addition, in Chaha, [p] is the reflex of a former geminate *bb. Banksira (2000) further argues that the bilabial phoneme is the sonorant $/ \beta /$ for Chaha, which has $[\mathrm{b}]$ as an allophone. 
contrast in coronal and velar stops between voiceless plain stops, voiceless ejectives and voiced stops: /t t' d k k' g/. Laryngeal harmony constraints are also attested in other languages, such as Kera, Ngizim, Hausa, Ijo, Aymara, Zulu (Hansson 2001b; MacEachern, 1997, 1999; Rose \& Walker, 2004), and as dissimilatory constraints in Sanskrit, Cuzco Quechua (MacEachern, 1997 [1999]) and Muna (Pater \& Coetzee, 2005). Chaha and Amharic differ in the scope of the LC. In Chaha, all coronal and velar stops are restricted in combination, but in Amharic, the verb root may not contain two contrasting voiceless oral stops with different laryngeal properties (i.e., $\left./ \mathrm{t} / / \mathrm{k}^{\prime} /\right)$.

Both the POAC and the LC have specific properties typical of co-occurrence constraints on words. First, the constraints are not exceptionless, and show gradient effects. Some places of articulation have more exceptions than others. This has been amply demonstrated for the POAC in Arabic by Greenberg (1950), McCarthy (1994), Pierrehumbert (1993), Frisch, Pierrehumbert, and Broe (2004) and Bachra (2001). Second, the constraints have a stronger effect in adjacent positions than in nonadjacent ones. Again, this has been shown for the Arabic place of articulation constraints. Finally, the constraints are root-bound. They show no evidence of operating across word-boundaries. The following examples illustrate that two labials, two coronal sonorants, and two alveolar stops with differing laryngeal features are attested in the languages:

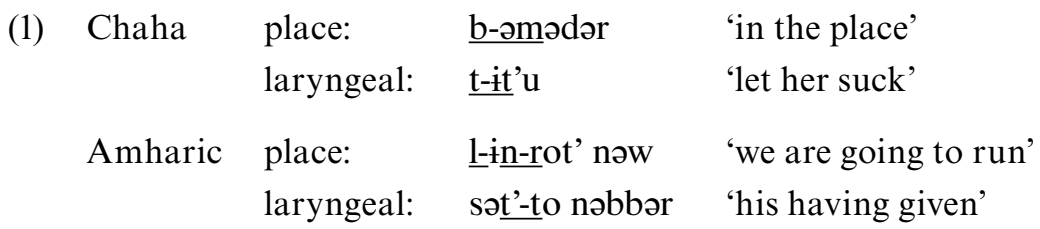

The fact that the POAC and LC consonant combinations may arise across morpheme boundaries suggests that frequency of combination may not constitute a large factor in potential speech error rates. Speakers of the language do use sequences in other positions that are dispreferred by the constraints within roots. In fact, the affix / $t(\partial) /$ is an exceptionally frequent prefix/suffix in both languages, with multiple uses (2sg.fem. subject, reciprocal, reflexive-passive, converb, preposition, etc.). Other frequent prefixes and suffixes are kə-, lə-, bə-, si-, al-, -n in Amharic and bə-, nə-, -nə, -m in Chaha.

\section{1 \\ Databases}

Evidence for the constraints is based on an assessment of two databases created by the authors. The Amharic corpus consisted of 4244 verbs taken from Kane's (1990) Amharic-English dictionary. The analysis was performed over 1874 nonreduplicative triliteral verb roots. In Semitic languages, the root consists of three consonants (or two or four), which combine with vowels in different positions to produce aspectual/tense distinctions in the verb, as well as other nominal/adjectival forms. For example, a root /dgm/ in Amharic produces the verb forms dəggəmə 'he repeated', ji-dəgm-al 'he repeats', 迁-dgəm 'let him repeat', dəgaggəmo 'he reviewed' and the nouns dəgəoma 
'recitation', dəgim 'repetition', diggami 'something done more than once', adjective diggim 'repeated', and so on. This combinatorial characteristic of the language is useful in that it underplays the role of syllable or word position in assessment of the co-occurrence constraints. The remainder of the roots in the dictionary were either reduplicative (repetition of root consonants) or were quadriliteral, with four consonants. The Chaha corpus consisted of 855 verbs taken from Leslau (1979), Banksira (2000), and the author's field notes. The analysis was performed over 303 nonreduplicative triliteral verb roots. The Chaha database is significantly smaller, as it is a less well-studied and less widely spoken language than Amharic and does not have a significant written tradition. Although the constraints may also be operative in nouns, we focused on verbs for two reasons. First, this is the traditional locus of place of articulation constraints in Semitic. Second, Chaha has many non-native nouns borrowed from neighboring Cushitic languages (Leslau, 1952), which may or may not conform to the constraint.

Before providing evidence for the constraints, it is useful to consider the phonemic inventories of the two languages and to consider the distribution of the consonants within verb roots. The phonemic inventory of Amharic is given below.

\section{Table 1}

Amharic consonant inventory

\begin{tabular}{|c|c|c|c|c|c|c|}
\hline & Labial & Alveolar & $\begin{array}{c}\text { Palato-alveolar } \\
\text { /palatal }\end{array}$ & Velar & $\begin{array}{l}\text { Labialized } \\
\text { Velar }\end{array}$ & Laryngeal \\
\hline Stops & $\mathrm{b}$ & $\mathrm{t} \quad \mathrm{d}$ & & $\mathrm{k} \quad \mathrm{g}$ & $\mathrm{k}^{\mathrm{w}} \mathrm{g}^{\mathrm{w}}$ & \\
\hline Affricates & & & tf क & & & \\
\hline Fricatives & $\mathrm{f}$ & S Z & $\int 3$ & & & $\mathrm{~h}$ \\
\hline Ejectives & & $\begin{array}{l}\mathrm{t}^{\prime} \\
\mathrm{s}^{\prime}\end{array}$ & ts' & k' & $\mathrm{k}^{\prime \mathrm{w}}$ & \\
\hline Nasal & $\mathrm{m}$ & $\mathrm{n}$ & $\mathrm{n}$ & & & \\
\hline Liquid & & $1 \mathrm{r}$ & & & & \\
\hline Glide & $\mathrm{w}$ & & $\mathrm{j}$ & & & \\
\hline
\end{tabular}

The sounds [\$] and [3] are listed as phonemes, but alternate as quasi-free variants. The sounds / $\mathrm{h} /$ and /s'/ are rare, particularly in verb roots. The Chaha inventory is similar, but has a series of labialized and palatalized consonants not present in the Amharic inventory: 
Table 2

Chaha consonant inventory

\begin{tabular}{|c|c|c|c|c|c|c|c|}
\hline & Labial & $\begin{array}{l}\text { Labialized } \\
\text { Labial }\end{array}$ & Alveolar & $\begin{array}{l}\text { Palato- } \\
\text { alveolar } \\
\text { /palatal }\end{array}$ & $\begin{array}{l}\text { Palatalized } \\
\text { Velar }\end{array}$ & Velar & $\begin{array}{l}\text { Labialized } \\
\quad \text { Velar }\end{array}$ \\
\hline Stops & b & $b^{w}$ & $\mathrm{t} \quad \mathrm{d}$ & & $k^{j} \quad g^{j}$ & $\mathrm{k} \quad \mathrm{g}$ & $\mathrm{k}^{\mathrm{w}} \quad \mathrm{g}^{\mathrm{w}}$ \\
\hline Affricates & & & & t5 $\mathrm{b}$ & & & \\
\hline Fricatives & $f$ & $f^{w}$ & $\mathrm{~S} \quad \mathrm{Z}$ & $\int 3$ & $\left(x^{\mathrm{j}}\right.$ & $\mathrm{x}$ & $\left.\mathrm{x}^{\mathrm{w}}\right)$ \\
\hline Ejectives & & & $t^{\prime}$ & tf' & $k^{j j}$ & $\mathrm{k}^{\prime}$ & $\mathrm{k}^{\mathrm{w}}$ \\
\hline Nasal & $\mathrm{m}$ & $\mathrm{m}^{\mathrm{w}}$ & $\mathrm{n}$ & & & & \\
\hline Liquid & & & $\mathrm{r}$ & & & & \\
\hline Glide & $\mathrm{w}$ & & & $\mathrm{j}$ & & & \\
\hline
\end{tabular}

The sound [n] is derived from / $\mathrm{r} /$ (Petros, 1996), but does contrast in a few words (Banksira, 2000). The sounds [x] and [k] alternate. Banksira (2000) analyzes / $\mathrm{x} /$ as the phoneme and $[\mathrm{k}]$ as an allophone. The sounds $[\mathrm{b}]$ and $[\beta]$ also alternate - Banksira analyzes $/ \beta /$ as the phoneme and [b] as its allophone, appearing word-initially or postnasally. In addition, there is a series of palatal/palatalized or labialized consonants in both languages, which are probably derived via processes of palatalization or labialization. Their distribution in verb roots is heavily skewed towards initial or medial position. For example, in our corpus of Amharic triconsonantal verbs, $/ \mathrm{g}^{\mathrm{W}} / \mathrm{has}$ 64 occurrences in first root position and zero in third root position. Finally, the glides /j w/ have irregular phonology, often surfacing as vowels or palatalization/labialization rather than glides. They are excluded for this reason.

This study examined only the 14 evenly distributed, most frequent consonants. Evenly distributed refers to the ability of the consonants to occur in all three root positions in relatively unrestricted fashion, unlike the glides or palatal consonants discussed above which have zero or few attestations in particular positions. The list contains only stops, fricatives, nasals, and liquids, with no palatalized or labialized sounds, and no glides. In order to establish which consonants were most frequent in verb roots, frequency values for each consonant were calculated by examining the total number of occurrence in each of the three root positions in the verbs in the database. Allophonic consonants in Chaha are shown in parentheses. The following table provides the resulting data, with consonants listed from most frequent to least frequent in terms of total number of occurrences. 


\section{Table 3}

Frequencies of Amharic and Chaha consonants in database

\begin{tabular}{|c|r|r|r|r|}
\hline Amharic & Total & C1 & C2 & C3 \\
\hline r & 485 & 52 & 191 & 242 \\
\hline l & 404 & 87 & 174 & 143 \\
\hline m & 354 & 135 & 113 & 106 \\
\hline b & 327 & 95 & 120 & 112 \\
\hline n & 324 & 113 & 81 & 130 \\
\hline s & 320 & 108 & 82 & 130 \\
\hline t' & 309 & 86 & 95 & 128 \\
\hline d & 294 & 110 & 95 & 89 \\
\hline k' & 287 & 100 & 69 & 118 \\
\hline g & 269 & 93 & 115 & 61 \\
\hline f & 260 & 78 & 85 & 97 \\
\hline t & 249 & 53 & 65 & 131 \\
\hline z & 185 & 69 & 57 & 59 \\
\hline k & 177 & 61 & 75 & 41 \\
\hline Total & $\mathbf{4 2 4 4}$ & $\mathbf{1 2 4 0}$ & $\mathbf{1 4 1 7}$ & $\mathbf{1 5 8 7}$ \\
\hline
\end{tabular}

\begin{tabular}{|l|r|r|r|r|}
\hline Chaha & Total & C1 & C2 & C3 \\
\hline r (n) & 180 & 40 & 68 & 72 \\
\hline s & 68 & 27 & 13 & 28 \\
\hline t' $^{\prime}$ & 66 & 21 & 25 & 20 \\
\hline f & 60 & 25 & 20 & 15 \\
\hline b & 54 & 17 & 24 & 13 \\
\hline d & 54 & 18 & 19 & 17 \\
\hline k' & 54 & 23 & 16 & 15 \\
\hline m & 51 & 16 & 19 & 16 \\
\hline g & 51 & 25 & 19 & 7 \\
\hline k (x) & 42 & 23 & 15 & 4 \\
\hline t & 30 & 13 & 8 & 9 \\
\hline z & 20 & 9 & 7 & 4 \\
\hline & & & & \\
\hline & & & & \\
\hline Total & $\mathbf{7 3 0}$ & $\mathbf{2 5 7}$ & $\mathbf{2 5 3}$ & $\mathbf{2 2 0}$ \\
\hline
\end{tabular}

Certain consonants do show uneven distribution within this list. For example, the liquids are less common in initial position compared to the two other positions. Nevertheless, as these are the most frequent consonants overall, their total occurrence in initial position is comparable to that of other consonants.

\section{2}

\section{Observed/Expected ratios}

The analysis of the presence of a constraint was calculated using the Observed/Expected ratio (Frisch, 1996; Frisch, Pierrehumbert, \& Broe, 2004; Pierrehumbert, 1993). This ratio compares the number of attested verbs that contain a pair of consonants to the number of verbs that would be expected by chance to contain that pair, taking into account the frequency of each individual consonant in the database. Co-occurrence of a pair of consonants is unrestricted if the value of $\mathrm{O} / \mathrm{E}$ is equal to or greater than one. The presence of a constraint is indicated if the value of $\mathrm{O} / \mathrm{E}$ is near zero. The classes of consonants used for the place of articulation are as follows:

(2) Place of Articulation Constraint classes

Labial — b m f

Coronal stops $-\mathrm{t} t$ ' d

Coronal fricatives $-\mathrm{s} z$ 
Coronal sonorants - $\mathrm{r} n \mathrm{l}$

Velar-k k’ g

Coronal stops and fricatives are often grouped as a single class of obstruents in discussions of Arabic (Frisch, Pierrehumbert, \& Broe, 2004; Greenberg, 1950). Following Yip (1989) and Padgett (1995), we divide coronal obstruents into two groups.

The following table provides the Observed/Expected Ratios for place of articulation for Amharic. $\mathrm{C} 1 \mathrm{C} 2$ refers to the first two consonants of the triconsonantal root, $\mathrm{C} 2 \mathrm{C} 3$ to the second and third and $\mathrm{C} 1 \mathrm{C} 3$ to the nonadjacent pairs in first and third position.

Table 4

Observed/Expected ratios for POAC constraint in Amharic

\begin{tabular}{|l|c|c|c|c|}
\hline & C1C2 & C2C3 & C1C3 & Total \\
\hline Labials & 0.029 & 0.028 & 0.345 & 0.134 \\
\hline Coronal Fricatives & 0.027 & 0.036 & 0.309 & 0.124 \\
\hline Coronal Sonorants & 0.024 & 0.126 & 0.875 & 0.342 \\
\hline Coronal Stops & 0.360 & 0.032 & 0.637 & 0.343 \\
\hline Velar Stops & 0.000 & 0.000 & 0.000 & 0.000 \\
\hline Grand Total & $\mathbf{0 . 0 8 8}$ & $\mathbf{0 . 0 4 4}$ & $\mathbf{0 . 4 3 3}$ & $\mathbf{0 . 1 8 8}$ \\
\hline
\end{tabular}

Chi-squares were performed for each place of articulation, collapsing across position, and were statistically significant $(p<.00019)$, indicating that attested combinations occurred less often than expected given the frequency of occurrence of the individual phonemes in the database. Each of the three positions was also attested less often than expected, including the nonadjacent C1C3 position, $\chi^{2}(1)=19.019, p<.00001$.

The Observed/Expected Ratio table for Chaha is given below. It is clear that the constraint is absolute in adjacent positions, and for particular classes - coronal fricatives and velar stops. Unlike Amharic, Chaha has no contrast among coronal sonorants, so this group is left out. No chi-squares were necessary due to the 0 results.

\section{Table 5}

Observed/Expected ratio for POAC constraint in Chaha

\begin{tabular}{|l|c|c|c|c|}
\hline & $\mathbf{C 1 C 2}$ & $\mathbf{C 2 C 3}$ & $\mathbf{C 1 C 3}$ & Total \\
\hline Labials & 0 & 0 & 0.356 & 0.119 \\
\hline Coronal Fricatives & 0 & 0 & 0 & 0 \\
\hline Coronal Stops & 0 & 0 & 0.587 & 0.196 \\
\hline Velar Stops & 0 & 0 & 0 & 0 \\
\hline Grand total & $\mathbf{0}$ & $\mathbf{0}$ & $\mathbf{0 . 2 3 6}$ & $\mathbf{0 . 0 7 9}$ \\
\hline
\end{tabular}

Language and Speech 
From these results, it is clear that both languages show evidence of a place of articulation (POAC) constraint. In addition, both languages have zero combinations of velars. Finally, both languages show lower $\mathrm{O} / \mathrm{E}$ ratios in adjacent positions, consistent with analyses of Arabic (Frisch, Pierrehumbert, \& Broe, 2004; McCarthy, 1994; Pierrehumbert, 1993) and Tigrinya (Buckley, 1997).

The laryngeal constraint has not previously been reported for Amharic, but has been reported for Chaha (Rose \& Walker, 2004). An analysis of nonhomorganic pairs of consonants in Amharic verb roots was conducted to detect evidence of a laryngeal constraint. Homorganic pairs would also violate the place of articulation constraint, so these would be disfavored independently. The results are shown below, with significant squares shaded.

\section{Table 6}

Observed/Expected ratios for laryngeal constraint in Amharic

\begin{tabular}{|l|c|c|c|c|}
\hline & C1C2 & C2C3 & C1C3 & Total \\
\hline $\begin{array}{l}\text { different [cg] [voice] } \\
\text { k' d t'g }\end{array}$ & 1.09 & 0.94 & 1.15 & 1.06 \\
\hline $\begin{array}{l}\text { different [voice] } \\
\text { k d t g }\end{array}$ & 1.57 & 0.82 & 1.11 & 1.17 \\
\hline $\begin{array}{l}\text { different [cg] } \\
\text { k t' t k' }\end{array}$ & 0.33 & 0.25 & 0.98 & 0.52 \\
\hline Total & $\mathbf{1 . 0 0}$ & $\mathbf{0 . 6 7}$ & $\mathbf{1 . 0 8}$ & $\mathbf{0 . 9 2}$ \\
\hline
\end{tabular}

Chi-squares show significant results for adjacent voiceless stop combinations, $\chi^{2}(1)=9.674, p<.002$, but not for voiceless stops in $\mathrm{C} 1-\mathrm{C} 3$ nonadjacent position, $\chi^{2}(2)=5.524, p<.07$. Therefore, Amharic shows a laryngeal constraint for a subset of consonant combinations - the voiceless stops in adjacent positions.

The results from Chaha heterorganic pairs are shown below with significant squares shaded:

Table 7

Observed/Expected ratios for laryngeal constraint in Chaha

\begin{tabular}{|l|c|c|c|c|}
\hline & $\mathbf{C 1 C 2}$ & $\mathbf{C 2 C 3}$ & $\mathbf{C 1 C 3}$ & Total \\
\hline $\begin{array}{l}\text { different [cg] [voice] } \\
\text { k' d t'g }\end{array}$ & 0.00 & 0.27 & 0.70 & 0.32 \\
\hline $\begin{array}{l}\text { different [voice] } \\
\text { k d t g }\end{array}$ & 0.96 & 0.00 & 2.27 & 1.08 \\
\hline $\begin{array}{l}\text { different [cg] } \\
\text { k t' t' k }\end{array}$ & 0.00 & 0.00 & 0.00 & 0.00 \\
\hline Total & $\mathbf{0 . 3 2}$ & $\mathbf{0 . 0 9}$ & $\mathbf{0 . 9 9}$ & $\mathbf{0 . 4 7}$ \\
\hline
\end{tabular}


A significant result for all positions overall was found, $\chi^{2}(3)=28.322, p<.0001$. As in Amharic, the nonglottalized pairs had the highest overall $\mathrm{O} / \mathrm{E}$ ratio and the voiceless pairs the lowest. Unlike Amharic, however, the adjacent positions are significant overall.

Different voicing was only significantly underrepresented in $\mathrm{C} 2 \mathrm{C} 3$ position. In conclusion, Chaha shows evidence of a laryngeal constraint, but primarily when the glottalic feature differs between the two consonants.

\section{Experiment 1: Amharic}

Two experiments were conducted in order to determine the psychological status of the co-occurrence constraints in Amharic and Chaha, as well as to investigate the roles of similarity and frequency in speech errors. These experiments were conducted using the speech elicitation method of syllable "tongue twisters" employed in Levitt and Healy (1985) and Wilshire (1999).

Experiment 1 investigates the speech error rate of Amharic consonant combinations. This experiment was designed to determine whether native speakers will apply the POAC and the Laryngeal constraint on voiceless stops (LC) when producing the stimuli (or twisters), as evidenced by a higher error rate for consonant combinations which violate these constraints than for consonant combinations which do not. Additionally, it will be determined whether such constraints are additive in nature, such that combinations which violate both constraints will be associated with more errors than combinations which violate only one constraint. And finally, it will be determined what role, if any, similarity and frequency play in speech errors involving combinations not subject to co-occurrence constraints.

The main hypothesis of the experiment, the Constraint hypothesis, states that speakers' productions will be negatively influenced by co-occurrence constraints identified through an analysis of dictionary corpuses. Higher error rates are predicted for consonant combinations that violate a co-occurrence constraint than those that do not. Each constraint will be tested separately. Notwithstanding, consonant combinations that are associated with co-occurrence constraints have two other features which may contribute to production difficulty, independently of the constraint itself: a high degree of similarity in terms of shared phonological features and low frequency of co-occurrence. Co-occurrence constraints are based on similarity between consonants, and they result in certain sequences occurring relatively infrequently. Therefore, to rule out the possibility that speech errors might be due either to unfamiliarity with the sequence (perhaps a motor/practice effect), or to basic production difficulties with similar consonants, the experiments were designed to control for these factors. In testing the Constraint hypothesis, consonant combinations which were not subject to a known co-occurrence constraint, but which were characterized by low frequency and high similarity, were used as a control. A statistical comparison of the error rates of the two groups will determine the relevance of the constraint. If higher error rates occur for the co-occurrence constraint combinations, the Constraint hypothesis will be supported, and the results can be construed as evidence for the psychological reality of the co-occurrence constraints. If higher error rates do not occur, the hypothesis is not 
supported, and co-occurrence constraints cannot be viewed as a factor independent from similarity and frequency in elicited speech errors.

An interesting secondary component to the Constraint hypothesis is the presence of two constraints in the languages under investigation, and their potential for interaction. Given the assumption that each co-occurrence constraint reflects a processing difficulty, it is hypothesized that consonant combinations which violate two constraints will cause more production difficulty than those combinations that violate only a single constraint. This is referred to as the Dual hypothesis. Higher error rates are predicted for consonant combinations that violate two co-occurrence constraints than those that violate only one.

In addition, since similarity is a factor known to impact error rates independently of co-occurrence constraints, it is hypothesized that it should also impact error rates when considered separately from the constraint combinations. Therefore, this experiment also tested the Similarity hypothesis, which states that combinations of similar consonants will cause more production difficulty than those which are dissimilar. Among those consonant combinations not subject to constraints, similar and dissimilar consonant combinations were compared, keeping frequency matched. Higher error rates were predicted for consonant combinations that are similar than those that are not.

Frequency was also tested as a possible factor affecting speech error rates. The Frequency hypothesis states that infrequent combinations of consonants will cause more production difficulty than frequent ones. Low frequency and high frequency combinations were compared, keeping similarity matched. Note that syllable position is not pertinent in the languages under investigation, since the constraints pertain to the lexical root, whose consonants appear in different syllabic positions in different paradigmatic surface forms. The only relevant effect of position is in relation to the triconsonantal sequence, that is, root-initial or root-final. Higher error rates are predicted for consonant combinations that are infrequent than those that are not. If the Similarity and Frequency hypotheses are supported, it is further evidence for the role of similarity and frequency in inducing speech errors. If these hypotheses are not supported, it could be the case that the co-occurrence constraints have grammatically encoded those combinations with the highest similarity, thereby reducing the effect among the remaining consonant combinations.

The list of tested hypotheses is summarized here for ease of reference:

(3) List of hypotheses

Constraint Higher error rates are predicted for consonant combinations that violate the co-occurrence constraint POAC than those that do not

Higher error rates are predicted for consonant combinations that violate the co-occurrence constraint LC than those that do not

Dual Higher error rates are predicted for consonant combinations that violate two co-occurrence constraints than those that violate one 
Similarity Higher error rates are predicted for consonant combinations that are phonologically similar than those that are dissimilar

Frequency Higher error rates are predicted for consonant combinations that are infrequent than those that are frequent

\section{1}

\section{Method}

\subsection{1}

\section{Subjects}

The subjects were 20 native speakers of Amharic (10 male/10 female) born and raised in Addis Ababa, aged between 18 and 34, with no reported eyesight or hearing problems. Subjects were reimbursed for their efforts. Their education level ranged from completion of Grade 8 through completion of Grade 12. Subjects spoke minimal English and no other Ethiopian language. Their ability to read was checked by asking them to read aloud a short paragraph. The experiment was conducted in Amharic with the help of an Amharic-speaking research assistant. The first author was present for the experiment.

\subsection{2}

\section{Materials}

The stimuli consisted of 90 consonant pairs arranged into CV syllable quadruples, which did not correspond to real words. Four twisters were obtained from each pair for a total of 360 . The CV syllables used the 14 most frequent, evenly distributed consonants /b, m, f, t, t' d, s, z, n, l, r, k, g, k'/ and the vowels [ə] and [a], the most frequent vowels in Amharic verbs. Consonants were arranged in either an ABBA/BAAB or an ABAB/BABA pattern. Corresponding vowels were arranged in the opposite pattern in one of two orders (either CDDC or DCDC). The Amharic writing system is a syllabic-based system, so each syllable corresponds to a single character. An example of the four possible quadruples are given in Table 8:

\section{Table 8}

Four twisters devised from /r, $1 /$ and $/ \mathrm{a}, \mathrm{\partial} /$

\begin{tabular}{|c|c|c|c|c|}
\hline Twisters & $\begin{array}{l}\text { ra lo ro la } \\
b . \Lambda<\Lambda\end{array}$ & $\begin{array}{l}\text { rə la lə ra } \\
\iota \wedge \Lambda<.\end{array}$ & $\begin{array}{l}\text { la ro lə ra } \\
\Lambda \zeta \Lambda \quad b\end{array}$ & $\begin{array}{c}\text { le ra ro la } \\
\Lambda t \cdot c \Lambda\end{array}$ \\
\hline $\begin{array}{l}\text { Consonant Pattern } \\
\text { r (A), } 1 \text { (B) }\end{array}$ & $\mathrm{ABAB}$ & ABBA & BABA & BAAB \\
\hline $\begin{array}{l}\text { Vowel Pattern } \\
\text { a (C), ə (D) }\end{array}$ & CDDC & DCDC & CDDC & DCDC \\
\hline
\end{tabular}

The consonant pairs were divided into six sets, listed in Table 9. In addition to the status labels listed below, Sets 5 and 6 were divided into low and high frequency sets and were used to test the Similarity and Frequency hypotheses (e.g., Set $5 \mathrm{sim} / \mathrm{low}$ freq vs. Set 6 dissim/low freq). 


\section{Table 9}

Classification of consonant pair stimuli

\begin{tabular}{|c|l|l|l|}
\hline Set & \multicolumn{1}{|c|}{ Label } & \multicolumn{1}{|c|}{ Description } & \multicolumn{1}{|c|}{ Status } \\
\hline 1 & LC-VLESS & $\begin{array}{l}\text { Heterorganic laryngeal-plain } \\
\text { voiceless stops (k' t, t' k) }\end{array}$ & Violates LC \\
\hline 2 & POAC & $\begin{array}{l}\text { Homorganic pairs (labials, coronal } \\
\text { sonorants, coronal fricatives, } \\
\text { coronal stops, velars) }\end{array}$ & Violates POAC \\
\hline 3 & DUAL & $\begin{array}{l}\text { Homorganic pairs of voiceless } \\
\text { coronal or velar stops (k' k, t t') }\end{array}$ & Violates LC and POAC \\
\hline 4 & LC-OTHER & $\begin{array}{l}\text { Heterorganic laryngeal } \\
- \text { voiceless-voiced stops }\end{array}$ & $\begin{array}{l}\text { Violates LC in Chaha, } \\
\text { but not Amharic }\end{array}$ \\
\hline 5 & SIM & $\begin{array}{l}\text { High similarity pairs with same } \\
\text { POA or same manner }\end{array}$ & $\begin{array}{l}\text { Comparison set } \\
\text { for constraint sets }\end{array}$ \\
\hline 6 & DISSIM & Low similarity pairs & Control set \\
\hline
\end{tabular}

The DUAL set consists of those combinations that violate both constraints. In determining the presence of the POAC constraint in the Amharic database (Table 3), the velar and coronal stop consonant categories included members of the dual category ( $\mathrm{k} \mathrm{k}$ ' and t t'), but these are separated here to better test the hypotheses. Set 4 (LC-OTHER) was isolated as a separate group to maintain a design correspondence with the Chaha experiment. However, due to the fact that this group does not violate the LC constraint in Amharic, it was not included in any of the statistical comparisons. Set 5 SIM was used to test the Similarity hypothesis, the hypothesis that similarity plays a role in speech errors in Amharic even when no co-occurrence constraint is present. Similar consonant combinations were assessed as those that share either place of articulation (only coronal stop/ fricative combinations since others are included in the constraint sets) or manner of articulation (e.g., stops, fricatives, nasals, liquids), a similarity method we term SIM-PM. Laryngeal differences are permitted. This reasoning is based on the assumption that manner classes and major place of articulation are stronger determinants of similarity than more minor features, such as voicing differences. The similar set consisted of oral stop-stop and fricative-fricative pairs

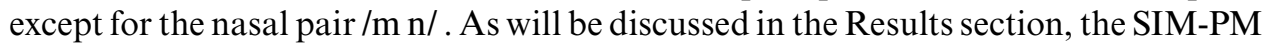
method of assessing similarity will be compared to the SPMV model (Bailey \& Hahn, 2005) and the SFC model (Frisch, Pierrehumbert, \& Broe, 2004) with respect to the speech error results.

In addition, each consonant combination is classified according to frequency in order to test the Frequency hypothesis, and to balance frequency in the comparison sets. Relative frequency for each pair was calculated based on the frequency of adjacent pairs in the database (see Table 10 below). In order to calculate relative frequency, the total number of occurrences of the consonant combination in adjacent position $(\mathrm{C} 1 \mathrm{C} 2+\mathrm{C} 2 \mathrm{C} 3)$ was divided by the total number of consonant combinations in adjacent position in the database (2085) and multiplied by 100 . The consonant 
pairs were classified as "low frequency" if both orders of the consonant pair had a relative frequency of 0.5 or less and "high frequency" if both orders of the pair had a relative frequency over 0.5 . Some pairs fell into a Low / High group - a combination in which one direction is low and the other is high. For example the sequence /k' f/ has a frequency of 0.19 (low), whereas the reverse /f k'/ has a frequency of 0.58 (high). See Appendix A for example stimuli from each set.

Table 10

Amharic consonant sets

\begin{tabular}{|c|c|c|c|}
\hline & Frequency & \# of pairs & Set Members \\
\hline Set 1 - LC-vless & Low & 2 & $\mathrm{k}^{\prime} \mathrm{t} ; \mathrm{t}^{\prime} \mathrm{k}$ \\
\hline SET 2 - POAC & Low & 11 & $\begin{array}{l}\text { s z; r l; t d; b f; k' g; t’ d; } \\
\text { b m; m f; k g; n 1; n r }\end{array}$ \\
\hline SET 3 - DuAl & Low & 2 & $\mathrm{k}^{\prime} \mathrm{k} ; \mathrm{t}^{\prime} \mathrm{t}$ \\
\hline \multirow{2}{*}{ SET 4 - LAR-other } & Low & 1 & $\mathrm{k} \mathrm{d}$ \\
\hline & Low/High & 3 & $\mathrm{k}^{\prime} \mathrm{d} ; \mathrm{t} \mathrm{g} ; \mathrm{t}^{\prime} \mathrm{g}$ \\
\hline \multirow{3}{*}{$\begin{array}{l}\text { SET } 5 \text { - SIM } \\
\text { (match on place or manner) }\end{array}$} & Low & 6 & $\mathrm{f} \mathrm{z} ; \mathrm{z} \mathrm{d} ; \mathrm{t} \mathrm{s} ; \mathrm{z} \mathrm{t} ; \mathrm{s} \mathrm{f} ; \mathrm{s} \mathrm{d}$ \\
\hline & Low/High & 6 & t's; t k; b g; k b; t b; n m \\
\hline & High & 5 & $\mathrm{k}^{\prime} \mathrm{t}^{\prime} ; \mathrm{d} \mathrm{g} ; \mathrm{t}^{\prime} \mathrm{b} ; \mathrm{d} \mathrm{b} ; \mathrm{k}^{\prime} \mathrm{b}$ \\
\hline \multirow[b]{3}{*}{$\begin{array}{l}\text { SET } 6 \text { - DISSIM } \\
\text { (no match on place or manner) }\end{array}$} & Low & 4 & z k; z k’ t n; f g \\
\hline & Low/High & 15 & $\begin{array}{l}\text { z g; t’ f; s k’ k’ f; m z; f k; } \\
\text { f t; m k; s g; k’ m; f d; z r; } \\
\text { b n; n k; n d }\end{array}$ \\
\hline & High & 35 & $\begin{array}{l}\text { s b; l g; n f; t’ m; d m; t m; } \\
\text { g m; s k; s m; r k; r t; r m; } \\
\text { b r; g r; f r; d r; s r; k’ r; } \\
\text { t’ r; g n; k’ n; t’ n; z 1; 1 d; } \\
\text { n z; s n; 1 s; t 1; b l; k' 1; } \\
\text { l m; 1 k; f 1; z b; l-t' }\end{array}$ \\
\hline Total & & 90 & \\
\hline
\end{tabular}




\subsection{3}

\section{Procedure}

The stimuli were presented to subjects on a DELL Inspiron 4000 laptop computer using the DMDX program. The items were written in black Ethiopic script (EthioSoft ${ }^{\mathrm{TM}}$ font, 36 point) on a white background with spaces between syllables. Each syllable was conveyed by a single unique symbol, as in the following example: $\boldsymbol{*} \mathbf{n} \boldsymbol{n}(=t a$ $k$ to $k a$ ). It is important to note that similar consonants such as $/ \mathrm{k} /$ and $/ \mathrm{k} / \mathrm{have}$ very different symbols, that is, $\mathbf{n}(\mathrm{k} ə)$ and $\mathbf{\Phi}(\mathrm{k} \partial)$. The chance of orthographically-induced reading errors is thus reduced. ${ }^{3}$ The frame duration of each quadruple was 130 ticks $(2.158 \mathrm{~s})$ with a delay between frames of 40 ticks $(0.664 \mathrm{~s})$. Stimuli were presented to each subject in a different random order, automatically generated by the DMDX program. The subjects received the following instructions (in Amharic):

(4) Instructions to subjects:

1. These are arbitrary sequences of Amharic syllables.

2. Read each presented item as they appear on the screen, maintaining the same rate of speech. Try to ignore errors and avoid self-correction.

The experiment was divided into three sessions of 120 twisters, each with a rest period between sessions. The experiment took less than 30 mins.

\subsection{4}

\section{Error transcription}

Recordings were broadly transcribed by the first author, who speaks some Amharic. Although more detailed transcription or acoustic analysis might reveal higher error rates or different kinds of errors (e.g., Frisch \& Wright, 2002; Goldstein, Pouplier, Chen, Saltzman, \& Byrd, 2007; Mowrey \& MacKay, 1990; Pouplier, 2003), the large number of twisters did not allow for this kind of detailed measurement. The transcriptions for two subjects chosen at random were double-checked by a native Amharic speaker, and the agreement with the original transcription was $98 \%$.

In reading the stimuli, all subjects divided the quadruple into two prosodic units of two syllables, with stress on the first syllable. Pilot tests in which subjects were instructed to read each syllable individually to avoid rhythmic patterns resulted in fatigue on the part of the speaker, and comments from the subjects that it was highly unnatural. Therefore, subjects were only given instructions to read the stimuli, and natural rhythm ensued. In addition to the prosody, speakers fairly consistently geminated either the second or fourth consonant in the twister if the preceding vowel was [ə]. The Ethiopic script does not normally indicate gemination; readers must recognize which words should be pronounced with gemination through context. The fact that subjects in the experiment did not geminate the third consonant is further confirmation that the twister was produced as two prosodic units, as the third

3 In the test set, there are two symbols, $\boldsymbol{\Lambda}$ (lo) and $\boldsymbol{\Lambda}$ (sə) (or $\boldsymbol{\Lambda}$ (la) and $\boldsymbol{\Lambda}$ (sa)), which are visually similar. Seven substitution errors occur in which $1 \rightarrow \mathrm{s}$. Nevertheless, although 1 appears in many combinations (e.g. $1 \mathrm{~g}, 1 \mathrm{t}$ ', $1 \mathrm{k}, 1 \mathrm{z}$ ), all of the substitution errors occur in $1 \mathrm{r}$ or $\mathrm{n} 1$ combinations, which points to the role of the POAC constraint in inducing errors, even those which may have an orthographic connection. 
consonant would be in initial position and ineligible for gemination. Amharic only has word-internal or word-final gemination. Nevertheless, gemination following [ə] in bisyllabic words is not required, e.g.: saga 'meat', and gemination is also possible following [a]: e.g. sassa 'he became thin'. Therefore, the consistent gemination does not appear to be correlated with existing lexical items, unless speakers were interpreting all bisyllabic sequences as $3^{\text {rd }}$ person masculine singular perfective verbal forms (the citation form in the dictionary), in which case gemination following [ə] would be required, e.g. sabba 'to be fat' (animal), and gemination following [a] would be excluded, e.g. sabo 'to draw, pull', except in reduplicative verb forms. The [a] in these verbs is the historical residue of a former $3^{\text {rd }}$ root consonant, a guttural. However, as there was no indication that subjects processed the sequences as verbs, a more likely explanation is a prosodic one. The rhythmic repetitive character of the experiment may have induced a prosodic balance between the two bisyllabic sequences. Since /a/ is a short vowel and /a/ a long one, gemination could have occurred following / / / to lengthen the stressed syllable on a par with the syllable containing /a/. A search of Kane's dictionary, taking into account possible conjugation patterns, failed to find any bisyllabic $\mathrm{CaCC}$ ə forms, whereas $\mathrm{C} ə \mathrm{CCa}$ forms are common.

\subsection{5}

\section{Error coding}

Each twister was divided into two tokens, corresponding to the prosodic units produced by the speakers, and each token was counted as "correct" or "incorrect." An analysis of error types and location of errors reveal that there are no errors which appear to cross the prosodic boundary between the two halves of the twister. Metathesis or exchange was a common error type, and none of these errors involved a switch between the second and third consonants. Errors were coded for general error type: vowel, consonant, syllable or other. "Syllable" involved complete exchange of two syllables: e.g. ka nə na kə $\rightarrow$ ka nə kə na. "Other" involved cases in which the subject failed to finish the twister, or added an extra syllable. Disfluent errors were not counted. Consonant errors were coded for specific type of error - substitution, exchange or featural transmission, and for location of the error. Details on error types are given in Appendix B and Appendix C. Substitution errors resulted when a feature or consonant not present in the stimuli was produced, for example, lo ra ro la $\rightarrow$ lə ra rə ta. Exchange errors involved metathesis of consonants, for example, sa mə $m a s ə \rightarrow$ sa mə sa mə. Featural transmission or change errors were assimilatory-type errors where a consonant took on the feature or features of another consonant. The error ga kə $k a$ gə $\rightarrow$ ga kə ga gə involves anticipation of the voicing of the fourth consonant. It could also be construed as intrusion of the segment /g/. All featural change errors have the potential to be ambiguous in this manner. There were a few featural exchange errors, which involved metathesis of features, rather than the entire consonant: e.g. sa gə sə ga $\rightarrow$ za kə sə ga, in which voicing is exchanged, but the place features remain in the correct order. The last error type, which we call " $1 / 2$ exchange," was one in which an exchange was begun, but then corrected: na t'ə t'a nə $\rightarrow$ na t' na t'a nə. In this example, it appears as if there is a beginning of the exchange of the third and fourth consonants, but the subject only gets as far as the first one, then produces the correct syllable sequence. This error could also be construed as featural transmission from the fourth consonant to the third and then self-correction. Due to 
this indeterminacy, these are treated separately. Some tokens contained more than one consonant error. Double errors involve an exchange in combination with either substitution or featural transmission, e.g. zə na $z a n$ nə $\rightarrow$ zə na $b a$ zə in which the final two consonants have switched position, but in addition the $/ \mathrm{n} /$ has been replaced with [b], or two substitutions in the same token. The analysis reported here does not distinguish between tokens with one error and tokens with more than one error (but see Appendix B for double consonant errors - 10 in total).

\section{2}

\section{Results}

Although all subjects completed the task, there were some high error rates, which may have been due to nervousness with the task. Subjects with error rates over $13 \%$ were excluded from analysis, leaving 14 subjects (6 were excluded, with error rates from $18-25 \%$. Thirteen percent was the same criterion used in the Chaha experiment). Individual error rates of remaining subjects ranged from $1.5 \%$ to $11 \%$, with an average error rate of $6.9 \%$. Among the 14 subjects, the overall rate of consonant errors was $2.2 \%$ and that of vowel errors was $5 \%$. These error rates are consistent with other speech error studies (Dell, 1984, Wilshire, 1999). ${ }^{4}$ There was no indication of fatigue or practice effects, $t(13)=1.62, p>.129$. The results for each set of consonants are shown below. The tokens obtained from sequences that had Low/High frequency rates (see Table 10) were assigned the appropriate frequency (low or high frequency) for purposes of analysis. Error rates greater than 5\% are shaded. LC-OTHER is maintained as a separate category, since this combination is a constraint violation in Chaha.

Table 11

Amharic consonant error corpus

\begin{tabular}{|l|c|c|c|c|c|}
\hline & Frequency & $\begin{array}{c}\text { Total tokens } \\
\text { with errors }\end{array}$ & Total pairs & $\begin{array}{c}\text { Total tokens } \\
\text { produced }\end{array}$ & Error rate \\
\hline 1- LC-VLESS & Low & 12 & 4 & 224 & 0.0536 \\
\hline 2- POAC & Low & 96 & 22 & 1232 & 0.0779 \\
\hline $3-$ DUAL & Low & 34 & 4 & 224 & 0.1518 \\
\hline \multirow{2}{*}{$4-$ LC-OTHER } & Low & 1 & 5 & 280 & 0.0036 \\
\cline { 2 - 6 } & High & 2 & 3 & 168 & 0.0119 \\
\hline \multirow{2}{*}{ 5- SiM } & Low & 8 & 18 & 1008 & 0.0079 \\
\cline { 2 - 6 } & High & 11 & 16 & 896 & 0.0123 \\
\hline \multirow{2}{*}{ 6- Dissim } & Low & 18 & 23 & 1288 & 0.0140 \\
\cline { 2 - 6 } & High & 44 & 85 & 4760 & 0.0092 \\
\hline \multirow{2}{*}{ Summary } & & $\mathbf{2 2 6}$ & $\mathbf{1 8 0}$ & $\mathbf{1 0 0 8 0}$ & $\mathbf{0 . 0 2 2 4}$ \\
\hline
\end{tabular}

4 For example, Dell (1984) found 3\% on noncritical pairs and $8 \%$ on critical pairs using the SLIPs technique, Wilshire (1999) had an error corpus of $4.5 \%$ of words uttered in the experiment. 
A vowel error corpus was also created, but there were no significant error rates based on consonant combination type. Although consonant errors were coded for type (i.e., exchange, featural transmission, etc.), type results will not be addressed in this paper. Our goal was to assess the effects of constraints, similarity, and frequency in inducing errors. Overall, exchange errors were the most frequent, constituting 89/226 errors. Exchange errors do not improve violations of constraints, so it is not the case that errors necessarily result in an improved sequence. See Appendix B for error type results per set, and Appendix $\mathrm{C}$ for specific errors per consonant.

\section{3}

\section{Analysis}

The experiments were designed to test the roles that similarity, frequency, and the presence of one or more constraints play on speakers' productions of tongue twisters. In order to test each of the three factors in turn, the groups being compared must be matched on the other two factors. To achieve this goal, the mean and the $95 \%$ confidence intervals around the mean were calculated for the properties of similarity and frequency for each set. Since the confidence intervals for the sets under comparison overlapped for these properties, it is assumed that the sets share comparable values. For the Constraint hypothesis and the Dual hypothesis, it was necessary to isolate the presence or absence of a constraint violation from the factors of similarity and frequency. The Constraint hypothesis maintains that the presence of a phonological constraint on consonant co-occurrence will result in a higher error rate than combinations not subject to a constraint (all else being equal) and the Dual hypothesis maintains that combinations that violate two constraints will result in a higher error rate than those that violate just one. Fisher's Exact test was used to analyze two-by-two contingency tables for inequality of error probabilities. For example, Fisher's Exact test will determine if the proportion of errors in the POAC set (constraint set) is greater than the proportion of errors arising from the low-frequency combinations in the SIM set (nonconstraint set). All comparisons were tested for significance at Bonferroniadjusted $\alpha$ levels to maintain a family $\alpha$-level of 0.05 . A total of 18 comparisons were made; nine for the entire error corpus and nine for the consonant error corpus subset, although we report only on the consonant error corpus here. Anything reported as significant for the constraint hypothesis had a $p$-value less than .0056 (.05/9).

For the Constraint hypothesis (see (3)), the constraint sets LC-vLESS and POAC were each compared against the low frequency members of Set 5-SiM, the set of consonant combinations which also had high similarity, but did not violate constraints. Similar consonants were those that shared the same place of articulation but different manner (i.e., $/ \mathrm{s} \mathrm{t} /$ ) or same manner but different place of articulation (i.e., $/ \mathrm{b} \mathrm{k} /$ ). The constraint set LC-VLESS had significantly more errors (12 out of 224 productions) than the control set ( 8 out of 1008 productions; $p<.0001$, Fisher's Exact test). Likewise, the constraint set POAC also had more errors ( 96 out of 1232 productions) than the control set ( 8 out of 1008 productions); $p<.0001$, Fisher's Exact test). ${ }^{5}$

5 A reviewer suggested that Set 2 might have a higher error rate than the control Set 5 due to Set 2 containing individual consonants not present in Set 5 that might have intrinsically higher error 
As for the Dual hypothesis, Set 3 - DuAL had double the error rate of Set 2-POAC (34 out of 224 productions and 96 out of 1232 productions, respectively; $p=.0008$, Fisher's Exact test) and almost triple the error rate of Set 1-LC-VLESS (12 out of 224 productions; $p=.0009$, Fisher's Exact test). Set 3-DuAL had significantly higher error rates than Set 5 -SIM ( 8 out of 1008 productions; $p<.0001$, Fisher's Exact test).

To summarize, the consonant combinations violating constraints had significantly higher error rates than those combinations not subject to constraints, but which were also highly similar with low frequency. In addition, the Set 3-DuAL category with two constraint violations had significantly higher error rates than each of the categories with single constraint violations, Set 2-POAC and Set1-LC-vLESS. Both the Constraint hypothesis and the Dual hypothesis were confirmed.

Based on previous research, the Similarity hypothesis predicts that combinations of similar consonants would result in a higher error rate than more dissimilar consonants. To test this, it was necessary to isolate similarity from the factors of constraint violation and frequency. Consonant combinations with high similarity rates were assessed against combinations with low similarity (using the SIM-PM method) where the frequency matched. The proportion of errors for high similarity /low frequency consonant pairs (8 errors out of 1008 productions) was not significantly different than the proportion of errors for low similarity/ low frequency consonant pairs (18 errors out of 1288 productions; $p=.233$, Fisher's Exact test). Likewise, there was no difference in error probabilities for high versus low similarity with high frequency: (11 errors out of 896 productions, 44 errors out of 4760 productions, respectively; $p=.358$, Fisher's Exact test). No significant results were found; the Similarity hypothesis was not confirmed.

Turning to the Frequency hypothesis, it was necessary to isolate frequency from the factors of constraint violation and similarity. Consonant combinations with low frequency were assessed against combinations with high frequency where similarity matched. There was no difference in error probabilities for high versus low frequency with low similarity: (44 errors out of 4760 productions, 18 errors out of 1288 productions, respectively; $p=.119$, Fisher's Exact test), nor for high versus low frequency with high similarity: (11 errors out of 896 productions, 8 errors out of 1008 productions, respectively; $p=.365$, Fisher's Exact test). No significant effect of frequency on speech error rate was found when co-occurrence constraints were excluded, meaning that the Frequency hypothesis was not supported.

Since other methods of computing similarity are more nuanced, they may reveal significant error probabilities that the SIM-PM method did not. This could affect all the comparisons, since it determines how nonconstraint consonant combinations are divided into sets. Post hoc analyses using the two other methods, the SpMV

rates, such as coronal sonorants. We therefore excluded stimuli that contained sonorants or consonants not present in the other set when making comparisons between Sets 2 and 5, namely the pairs: $\mathrm{r} 1,1 \mathrm{r}, \mathrm{n}$ 1, $1 \mathrm{n}, \mathrm{n} \mathrm{r}, \mathrm{r} \mathrm{n}, \mathrm{m}$ b, b m, m f, f m, g k', and k' $\mathrm{g}$ from Set 2 and $\mathrm{n} \mathrm{m}$ from Set 5 . The resulting analysis showed that the smaller Set 2 (s z, z s, t d, d t, t' d, d t', k g, g k, b f, f b) still had a significantly higher error rate than Set 5 (41 errors per 560 productions vs. 8 errors per 952 productions, Fisher's Exact test; $p<.0001)$. 
method (Bailey \& Hahn, 2001) and the Shared Feature Class (SFC) method (Frisch, Pierrehumbert, \& Broe, 2004) were performed. For the SPMV method, a similarity rating of 1-4 was used. Four classes of feature sets corresponding to place, manner, sonorant, and laryngeal properties were used to calculate the number of features that differentiated consonants. The only adjustment to the SPMV method was to use three laryngeal classes instead of two for the voiced/voiceless category, since Amharic has ejective consonants. A rating of 1 or 2 (feature differences) was considered similar and a rating of 3 or 4 (feature differences) was considered dissimilar. The only adjustment in the constraint categories was to remove the pair / $\mathrm{f} \mathrm{m} /$ from analysis, since it had a rating of 3, and other constraint pairs had a rating of 1 or 2 . In other categories, adjustments were made so that Set 5 contained only consonant pairs with a rating of 1 or 2 , and Set 6 only pairs with a rating of 3 or 4 . For all comparisons, there were no differences in the results between the SPMV method and the SIM-PM method. See Appendix D for details.

As for the SFC method, combinations with a similarity rating of 0.28 or above were considered similar. This was the minimum similarity rating for pairs in the POAC set. Those with a rating of less than 0.28 were considered dissimilar. Consonant sets were adjusted accordingly, so that Set 5 contained only pairs with 0.28 or above, whereas Set 6 contained only pairs with similarity below 0.28 . There was no difference in the results using the SFC method as opposed to the SIM-PM method for any of the comparisons. See Appendix D for details.

Since subjects divided the quadrisyllabic stimuli into two prosodic units, it is possible that some of the bisyllabic sequences corresponded to actual lexical items, and that familiarity with the lexical items led to fewer errors. A thorough search of Kane's dictionary was undertaken and all lexical items that corresponded to the stimuli $\left(\mathrm{C} ə \mathrm{C}_{\mathrm{i}}\left(\mathrm{C}_{\mathrm{i}}\right)\right.$ a or $\mathrm{CaC}$ ə forms) were identified. Of all the possible combinations of test consonants, there were 50 combinations that were unattested in the dictionary ( 24 of these constraint violations). However, in order to test whether lexical item attestation played a role in error rate independently of constraints, nonconstraint combinations were examined (Sets 5 and 6). As it was independently determined that similarity and frequency do not play a role in error rate, all nonconstraint combinations were grouped together, as shown in Table 12.

Table 12

Error rates corresponding to attested lexical items - non-constraint sets

\begin{tabular}{|c|c|c|c|}
\hline $\begin{array}{c}\text { Attested Lexical } \\
\text { Items }\end{array}$ & Number of pairs & Number of errors & Error rate \\
\hline 0 & 26 & 10 & .0069 \\
\hline 1 & 55 & 30 & .0097 \\
\hline 2 & 49 & 32 & .0117 \\
\hline 3 & 13 & 9 & .0124 \\
\hline 4 & 1 & 0 & 0 \\
\hline
\end{tabular}

Language and Speech 
The results show that there is no worse error rate when combinations correspond to zero or to one lexical item. Therefore, there is no evidence of a correspondence between attested lexical items and lower error rate when constraints are not present. ${ }^{6}$

In summary, the results revealed that there were significantly higher error rates for those consonant combinations that violated the Laryngeal Constraint and the Place of Articulation Constraint than for the control set, confirming the Constraint hypothesis. Furthermore, those combinations that violated both constraints had the highest error rate of all, significantly higher than either single constraint alone, confirming the Dual hypothesis, that the constraints have a cumulative effect. However, the Similarity and Frequency hypotheses were not confirmed. These hypotheses had predicted that, independent of the constraints, similar consonant combinations and less frequent consonant combinations respectively would result in high error rates.

\section{Experiment 2: Chaha}

\section{1 \\ Methods}

The Chaha experiment used the same methodology as the Amharic experiment. The hypotheses tested were the same as for Amharic: Constraint hypothesis, Dual hypothesis, Similarity hypothesis and Frequency hypothesis (see list in (3)). A few extra comparisons were done and will be pointed out where appropriate.

\subsection{1}

Subjects

The subjects were 20 native speakers of Chaha (14 male/ 6 female), born and raised in the Gurage Zone, aged between 18 and 35, with no reported eyesight or hearing problems. The Chaha subjects were bilingual in Amharic and spoke minimal English. Bilingual subjects were necessary due to the written nature of the experiment. Chaha is not generally a written language (apart from a few novels and the New Testament) but when written, the same Ethiopic script is used with some slight modifications for sounds not found in Amharic; students learn to read and write using Amharic. Education level was completion of Grade 8 up to completion of Grade 12. Subjects were reimbursed for their participation. The experiment was conducted in Chaha with a Chaha-speaking assistant. The first author was present for the experiment.

\subsection{2}

Materials

The stimuli consisted of 74 consonant pairs arranged into CV syllable quadruples, which did not correspond to real words. Four twisters were obtained from each pair for a total of 296. The CV syllables used the 12 most frequent, evenly distributed consonants, based on a frequency count of the Chaha database: / $\mathrm{b} \mathrm{m} \mathrm{f} \mathrm{t} \mathrm{t'} \mathrm{d} \mathrm{s} \mathrm{z} \mathrm{r}$ $\mathrm{k} \mathrm{g} \mathrm{k} \%$ The consonants [n] and [x] were also included, despite their quasi-allophonic status (of $/ \mathrm{r} /, / \mathrm{k} /$ ). Both occur in the surface form of verb roots, e.g. kəfətəm 'he

6 It was not possible to test for frequency of usage of the attested combinations. 
opened' or gənəzəm 'he became old'. The vowels were [ə] and [a]. Consonants were arranged in either an ABBA or a BABA pattern Corresponding vowels were arranged in the opposite pattern (either [a ə ə a] or [ə a ə a]).

The consonant pairs were classified according to the same five sets as in Amharic. The total was only 70, since four pairs were pulled from the analysis (see below). See Appendix A for example stimuli from each set.

Table 13

Chaha consonant sets

\begin{tabular}{|c|c|c|c|}
\hline & Frequency & \# of pairs & Set Members \\
\hline $\begin{array}{l}\text { SET } 1 \text { - LC-VLESS } \\
\text { (voiceless-ejective ) }\end{array}$ & Low & 2 & $\mathrm{k}^{\prime} \mathrm{t} ; \mathrm{t}^{\prime} \mathrm{k}$ \\
\hline SET 2 - POAC & Low & 4 & $\mathrm{~s} \mathrm{z} ; \mathrm{m} \mathrm{f} ; \mathrm{m} \mathrm{b} ; \mathrm{b} \mathrm{f}$ \\
\hline SET 3 - DuAL & Low & 6 & $\mathrm{t}$ d; k' k; k g; t' d; t' t; k' g \\
\hline \multirow{2}{*}{$\begin{array}{l}\text { SET } 4 \text { - LAR-OTHER } \\
\text { (voiced-voiceless } \\
\text { or voiced- ejective) }\end{array}$} & Low & 3 & $\mathrm{t} g ; \mathrm{t}^{\prime} \mathrm{g} ; \mathrm{k}^{\prime} \mathrm{d}$ \\
\hline & $\begin{array}{l}\text { Low/ } \\
\text { High }\end{array}$ & 1 & $\mathrm{k} \mathrm{d}$ \\
\hline \multirow{3}{*}{$\begin{array}{l}\text { SET } 5 \text { - SIM } \\
\text { (match on place or manner) }\end{array}$} & Low & 8 & $\mathrm{z}$ d; z t’; z t; g b; f z; t’ s; t s; t b \\
\hline & $\begin{array}{l}\text { Low/ } \\
\text { High }\end{array}$ & 2 & s f; s d \\
\hline & High & 7 & $\mathrm{k}^{\prime} \mathrm{t}^{\prime} ; \mathrm{d} \mathrm{b} ; \mathrm{k} \mathrm{b} ; \mathrm{d} \mathrm{g} ; \mathrm{t} \mathrm{k} ; \mathrm{k} \mathrm{b}^{\prime}$; t' b \\
\hline \multirow{3}{*}{$\begin{array}{l}\text { SET } 6 \text { - DISSIM } \\
\text { (no match on place or } \\
\text { manner) }\end{array}$} & Low & 3 & z k'; z k; k m \\
\hline & $\begin{array}{l}\text { Low/ } \\
\text { High }\end{array}$ & 7 & b z; k’ m; k’ f; f t; s m; m z; m g \\
\hline & High & 27 & $\begin{array}{l}\text { b s; d f; f g; k f; t' f; g s; g z; } \\
\text { k' s; k s; b r; d m; d r; f n; f r; } \\
\text { g n; g r; k' n; t’ n; k' r; r k; m r; } \\
\text { m t’ m t; r s; r t; r t’ r z }\end{array}$ \\
\hline Total & & 70 & \\
\hline
\end{tabular}

\subsection{3}

Procedure, transcription, coding

The procedure, transcription, and coding was the same as for Experiment 1. All subjects divided the quadruple into two prosodic units with stress on the first syllable. Unlike Amharic speakers, no gemination was noted for the Chaha speakers. Chaha does not have geminates, and this alleviates concerns that the subjects might have been processing the syllable twisters as "Amharic," due to the nature of the reading task. Furthermore, the fact that the experiment was conducted in Chaha, instructions were 
given in Chaha, and that the instructions specified the syllables as "Chaha syllables" reinforces the Chaha nature of their productions.

There were some reading problems with the consonant $[\mathrm{x}]$. Twenty-five consonant errors involved tokens with [x], 16 of which involved noncontextual substitution of [k] for [x]. Eight consonant errors occurred in which [x] substituted for [k]. Since [k] and $[\mathrm{x}]$ are allophonic, this may have been due to the allophonic status of the sounds. However, no such similar problem occurred with [n] and [r], which are also allophonic. [x] is not commonly used in Amharic and inexperience with this character may have led to more errors. In addition, the two symbols for $[\mathrm{k}]$ and $[\mathrm{x}]$ are similar. $[\mathrm{x}]$ is a modification of the symbol for [k]: $\mathbf{n}$ (kə) $\mathbf{n}$ (xə). Since noncontextual substitutions of this magnitude were uncommon, the conclusion is that the [x] errors were likely orthographic reading errors. Therefore, all tokens with $[\mathrm{x}]$ were removed from the analysis (total of 136 twisters for 17 speakers).

\section{2 \\ Results}

As with Experiment 1, all subjects completed the task successfully, but there were three subjects with error rates above 13\%. These subjects were excluded, leaving 17. Individual error rates of the remaining subjects ranged from $1.4 \%$ to $10 \%$, with an average of $4.4 \%$. The consonant error rate was $2.8 \%$ and the vowel error rate was $2.2 \%$. There was no indication of fatigue or practice effects, $t(16)=1.609, p>.127$. The results for each set of consonants are shown below; error rates above $5 \%$ are shaded. As with the Amharic experiment, errors are counted for each half of the twister, as the speakers divided the twisters into two prosodic units.

Table 14

Chaha consonant error corpus

\begin{tabular}{|l|c|c|c|c|c|}
\hline & Frequency & $\begin{array}{c}\text { Total tokens } \\
\text { with errors }\end{array}$ & Total pairs & $\begin{array}{c}\text { Total tokens } \\
\text { produced }\end{array}$ & Error rate \\
\hline 1 - LC-VLESS & Low & 17 & 4 & 272 & 0.0625 \\
\hline $2-$ POAC & Low & 35 & 8 & 544 & 0.0643 \\
\hline $3-$ DUAL & Low & 105 & 12 & 816 & 0.1287 \\
\hline \multirow{2}{*}{$4-$ LC-OTHER } & Low & 11 & 7 & 476 & 0.0231 \\
\cline { 2 - 6 } & High & 3 & 1 & 68 & 0.0441 \\
\hline \multirow{2}{*}{ (LC 1 + 4) } & Low & 28 & 11 & 748 & 0.0374 \\
\hline \multirow{2}{*}{ 5 - SIM } & Low & 26 & 18 & 1224 & 0.0212 \\
\cline { 2 - 6 } & High & 22 & 16 & 1088 & 0.0202 \\
\hline \multirow{2}{*}{$6-$ DisSIM } & Low & 5 & 13 & 884 & 0.0056 \\
\cline { 2 - 6 } & High & 43 & 61 & 4148 & 0.0103 \\
\hline \multirow{2}{*}{ Total } & & $\mathbf{2 6 7}$ & $\mathbf{1 4 0}$ & $\mathbf{9 5 2 0}$ & $\mathbf{0 . 0 2 8 0}$ \\
\hline
\end{tabular}


As with Amharic, the rates for Sets 1 and 2 have error rates above 5\%. Set 4-LC-OTHER, which does constitute a constraint set in Chaha, has an error rate below $5 \%$. In addition, the DuAL category in the Chaha chart includes those consonant combinations that violate LC-OTHER as well, namely [t' d, k' g, t d, k g]. Similarity to existing lexical items was not determined to be a factor in Chaha, due to the extreme paucity of forms in the experiment that corresponded to an actual word in Chaha. In particular, unlike Amharic, the $3^{\text {rd }}$ person masculine singular verb conjugation in Chaha occurs with a prefix or a suffix.

Fisher's Exact test was used to analyze two-by-two contingency tables for inequality of error probabilities for the Chaha results. All comparisons were tested for significance at Bonferroni-adjusted $\alpha$ levels to maintain a family $\alpha$-level of 0.05 . A total of 13 comparisons were made $(0.05 / 13)$. Any comparison reported as significant had a $p$-value less than .004 .

For the Constraint hypothesis (see (3)), the constraint Set 2-POAC had significantly more errors than the control set, Set 5-SIM (low frequency) (35 out of 544 productions; $p<.0001$, Fisher's Exact test). The LC set was divided into three test groups. The overall LC set (the full set of voiceless, voiced, and ejective stops) was tested against the control set, Set 5-SIM (low frequency), but did not have significantly more errors (28 out of 748 productions; $p=.0454$, Fisher's Exact test). This was despite showing evidence of a constraint in the database analysis of Chaha. The LC set was further subdivided into two groups: a voiceless set, which was the same as the LC set in Amharic, and a set containing combinations with voiced stops. The voiceless set had zero attestations in the Chaha database. The set of voiceless consonants 1-LC-VLESS did have significantly more errors (17 out of 272 productions) than the control set, Set 5-SIM (low frequency) (26 out of 1224 productions; $p=.0009$, Fisher's Exact test). However, Set 4 -LC-OTHER (voiceless-voiced and voiced-ejective) combinations, which did show evidence of a constraint in the database analysis of Chaha, did not have more errors (11 out of 476 productions) than the control set ( $p=.857$, Fisher's Exact test). In sum, the Constraint hypothesis was confirmed for POAC and the LC voiceless set. The Constraint hypothesis was not confirmed for the LC category containing combinations with voiced stops, or for the LC set as a whole.

As for the Dual hypothesis, comparisons of the Dual category with each of the single violation categories were significant: Set 3-DuAL (105 out of 816 productions) had more errors than Set 2-POAC ( 35 out of 544 productions; $p=.0001$, Fisher's Exact test). It also had more errors than overall LC (Sets $1+4)$ ( 28 out of 748 productions; $p<.0001$, Fisher's Exact test), and Set 1-LC-VLESS (17 out of 272 productions; $p=.0026$, Fisher's Exact test). Finally, Set 3-DuAL (105 out of 816 productions) had more errors than Set 5-SIM (26 out of 1224 productions; $p<.0001$, Fisher's Exact test). The Dual hypothesis was confirmed.

To test the Similarity hypothesis, consonant combinations with high similarity rates were assessed against combinations with low similarity (using the place/manner method) where the frequency matched. Fisher's Exact test showed that for combinations with low frequency, high similarity combinations had significantly more errors (26 out of 1224 productions) than low similarity (5 out of 884 productions; $p=.0029$, 
Fisher's Exact test). For high frequency combinations, high similarity combinations also had more errors (22 out of 1088 productions) than low similarity (43 out of 4148 productions), but fell short of a significant result ( $p=.0131$, Fisher's Exact test). When both frequency groups are combined, Set 5 - similar (48 errors out of 2312 productions) had significantly more errors than Set 6 - dissimilar (48 errors out of 5032 productions; $p=.0001$, Fisher's Exact test). Therefore, the Similarity hypothesis was confirmed when low frequency and high frequency items were combined, as well as for low frequency combinations separately, but it was not confirmed for high frequency combinations.

To test the Frequency hypothesis, consonant combinations with low frequency were assessed against combinations with high frequency where similarity matched. For combinations with high similarity, low frequency combinations did not have significantly more errors (26 out of 1224 productions) than high frequency (22 out of 1088 productions; $p=.885$, Fisher's Exact test). Among low similarity combinations, low frequency combinations did not have significantly more errors (5 out of 884 productions) than high frequency combinations (43 out of 4148 productions; $p=.252$, Fisher's Exact test). The Frequency hypothesis was not confirmed.

As with the Amharic experiment, similarity for Chaha consonant pairs was also calculated according to the SFC and SPMV methods. For the SPMv, similar results were found to the SIM-PM method employed in the experiment. One difference was that a significant result for similarity was found among high frequency pairs, but the low frequency pairs did not produce a significant result, the reverse of the result using SIM-PM. Nevertheless the combined similar group (high + low frequency) also had significantly more errors than the combined dissimilar group (high + low frequency). See Appendix D for details. As for the SFC method, consonant pairs were divided into similar $(0.23)$ and dissimilar $(<0.23)$. This split corresponded to the lowest rank found within the constraint set. As the Chaha inventory has more velars and labials than the Amharic one, overall similarity values were lower, as the SFC method takes inventory size into consideration in calculating shared feature classes. Results were the same as the other methods for all the comparisons except for the Similarity hypothesis comparisons, where no significant results were found. This was true even when the similarity cut-off was raised to 0.35. See Appendix D for details.

In summary, the results revealed that there were significantly higher error rates for those consonant combinations that violated the Place of Articulation Constraint than for the control set, confirming the Constraint hypothesis. As a whole, the LC group did not show evidence of a significantly higher error rate, but the subgroup LC-VLESS did, a partial confirmation of the Constraint hypothesis. Those consonants that violated both constraints had the highest error rate of all, significantly higher than either single constraint alone, confirming the Dual hypothesis. The Similarity hypothesis, which stated that similar consonant combinations, independent of the constraints, would result in higher error rates was partially confirmed. However, the Frequency hypothesis, which stated that less frequent combinations, independent of the constraints, would result in higher error rates, was not confirmed. 


\section{General discussion}

The results from both experiments confirmed the Constraint hypothesis: The consonant combinations that violated the POAC and the Laryngeal constraint on voiceless stops were associated with significantly higher error rates than consonant combinations which did not violate a constraint and which were matched on similarity and frequency. The expanded Laryngeal constraint in Chaha (LAR-OTHER), which included the plain voiceless-voiced and voiced-ejective combinations, did not show significantly high error rates, despite low $\mathrm{O} / \mathrm{E}$ ratios. There are several possible explanations for the lack of effect with Laryngeal-other. First, Chaha shows evidence for Laryngealother constraint with voiced-ejective pairs, but for voiced-voiceless only in $\mathrm{C} 2 \mathrm{C} 3$ position; it is possible that the voiced-voiceless combinations are responsible for the nonsignificant result. Nevertheless, the error rates for the two groups were comparable: 0.241 for voiced-ejective and 0.205 for voiced-voiceless, so this does not appear to be responsible for the result. Second, O/E ratios are based on underlying "root" representations, not surface representations. Chaha verbs exhibit a devoicing process that devoices penultimate consonants under certain conditions (see Banksira, 2000), leading to voicing mismatches in verbal paradigms. From the underlying root $/ \mathrm{gdr} /$, forms with [d] are found: jigadir 'he puts to bed' and those with devoiced [t]: gatoram 'he put to bed'. This process could undermine the effect of the LC-OTHER constraint, as it introduces violations in some members of the verbal paradigm. Finally, the similarity rating LC-OTHER according to the shared feature class method of computing similarity is very low compared to LC-VLESS (LC-OTHER ranges from 0.15 to 0.17 vs. 0.40 for LC-VLESS and a range of 0.24 to 0.42 for POAC). Thus, one would not predict the presence of a constraint on LC-OTHER from the SFC similarity rating.

Both languages confirmed that doubling up the constraints on a consonant combination led to double the error rate (the Dual hypothesis), and this occurred despite the inclusion of LC-OTHER in the DUAL category for Chaha. The high error rates for the DUAL category reflect the fact that both POAC and LC-VLESS had significantly high error rates, as in Amharic. The inclusion of the LC-OTHER category in the DUAL group did not affect this basic result. The Chaha results are also revealing as all the POAC combinations had zero frequency of $\mathrm{O} / \mathrm{E}$ ratios, and yet the greater error rate for the duals suggests that knowledge of the Laryngeal constraint did influence the error rate. The results thus support the Dual hypothesis that the effects of co-occurrence constraints are cumulative, and further support the hypothesis that co-occurrence constraints reflect processing difficulties which are additive in nature.

Neither language showed evidence of frequency impacting error rates (the Frequency hypothesis). This suggests that error rates cannot be directly attributed to lack of familiarity with the consonant combinations. However, the frequency levels between the consonants may be too close for a significant result to emerge, so it is prudent not to read too much into this result.

Turning to the Similarity hypothesis, only Chaha showed a significant impact of similarity on error rates, but only for low frequency pairs according to SIM-PM. High frequency pairs fell just short of a significant result. A significant impact of similarity on error rates for high frequency pairs but not for low frequency pairs was 
found according to SpMV. The $p$-value necessary to achieve significance was low (.004) due to the Bonferroni adjustment. When combined, the similar group had significantly higher error rates than the dissimilar group for both methods. Since the Similarity hypothesis was (partially) confirmed using both the SIM-PM method and the SPMV, but not with the SFC, the method of calculating similarity proved to be important. The main difference between the SFC and the other two methods is with respect to obstruent combinations, many of which are analyzed as dissimilar under the SFC but as similar under the other two methods. Since many obstruent combinations had high numbers of errors (i.e., $\mathrm{z} \mathrm{g}, \mathrm{s} \mathrm{k}, \mathrm{b} \mathrm{k}$ ), this appeared to be the reason for SFC failing to return significant error differences with respect to similarity. One conclusion to draw from this might be that the sonorant-obstruent division is more important in assessing similarity than other features, and should be weighted more heavily. The similarity results for Amharic are somewhat unexpected given previous research on similarity and error rates, and the fact that significant results were found for Chaha. The co-occurrence constraint combinations themselves are highly similar, and it may be the case that power issues are obscuring statistical sensitivity to error rate differences among the small group of nonconstraint high similarity combinations in Amharic.

\section{Conclusion}

Although Semitic languages are known to have co-occurrence restrictions on nonidentical consonant combinations, little psycholinguistic research has been performed on this aspect of their structure (although see Berent, Vaknin, \& Shimron, 2004, on a contrast between identical and "similar" consonants). The two experiments presented here shed light on the grammatical status of co-occurrence restrictions in two Semitic languages that have not been previously investigated using psycholinguistic methodology. The experiments reveal that speech errors occurred at a significantly higher rate for consonant combinations that violated co-occurrence constraints in the languages than for combinations that were simply highly similar or had low frequency of occurrence. From this we can conclude that the two co-occurrence constraints do influence the productions of speakers of Chaha and Amharic. Further, the result that doubling the constraint violations doubles the error rate suggests that the constraints are reflections in the grammar of the processing difficulty associated with these combinations.

manuscript received: 08. 02. 2005

manuscript accepted: 12.06 .2006 


\section{References}

ABD-EL-JAWAD, H., \& ABU-SALIM, I. (1987). Slips of the tongue in Arabic and their theoretical implications. Language Sciences, 9, 145-171.

ALDERETE, J. (1997). Dissimilation as local conjunction. Proceedings of Northeast Linguistic Society, 27, 17-31.

ARCHANGELI, D. (1984) [1988]. Underspecification in Yawelmani phonology and morphology. PhD dissertation, Cambridge, MA: MIT [Published, New York: Garland, 1988].

BAARS, B., MOTLEY, M., \& MacKAY, D. (1975). Output editing for lexical status from articifically elicited slips of the tongue. Journal of Verbal Learning and Verbal Behavior, 14, 382-391.

BACHRA, B. (2001). The phonological structure of the verbal roots in Arabic and Hebrew. Leiden: Brill.

BAILEY, T. M. \& HAHN, U. (2001). Determinants of wordlikeness: Phonotactics or lexical neighborhoods? Journal of Memory and Language, 44, 568-591.

BAILEY, T. M. \& HAHN, U. (2005). Phoneme similarity and confusability. Journal of Memory and Language, 52, 339-362.

BANKSIRA, D. P. (2000). Sound mutations: The morphophonology of Chaha. Amsterdam: John Benjamins Publishing Company.

BÉLAND, R., \& FAVREAU, Y. (1991). On the special status of coronals in aphasia. In C. Paradis \& J.-F. Prunet, (Eds.), Phonetics and phonology, Vol.2. The special status of coronals: Internal and external evidence (pp. 201-221). New York: Academic Press.

BENDER, M. L. (1974). Phoneme frequencies in Amharic. Journal of Ethiopian Studies, 12, 19-24.

BENDER, M. L. (1978). Consonant co-occurrence restrictions in Afroasiatic verb roots. In P. Fronzaroli (Ed.), Atti del secondo congresso internazionale di linguistica camito-semitica (pp.9-19). Firenze: Istituto di Linguistica e di Lingue Orientali.

BENDER, M. L., \& FULASS, H. (1978). Amharic verb morphology. East Lansing, MI: The African Studies Center, Michigan State University.

BERENT, I., EVERETT, D, \& SHIMRON, J. (2001). Do phonological representations specify variables? Evidence from the obligatory contour principle. Cognitive Psychology, 42, 1-60.

BERENT, I., VAKNIN, V., \& SHIMRON, J. (2004). Does a theory of language need a grammar? Evidence from Hebrew root structure. Brain and Language, 90, 170-182.

BERG, T. (1991). Redundant-feature coding in the mental lexicon. Linguistics, 29, 903-925.

BERKLEY, D. (1994). The OCP and gradient data. Studies in the Linguistic Sciences, 24, 59-72.

BERKLEY, D. (2000). Gradient obligatory contour principle effects. PhD dissertation, Northwestern University.

BLUMSTEIN, S. (1973). A phonological investigation of aphasic speech. The Hague: Mouton.

BROECKE, M. van den, \& GOLDSTEIN, L. (1980). Consonant features in speech errors. In Victoria A. Fromkin, (Ed.), Errors in linguistic performance (pp.47-65). San Diego: Academic Press.

BUCKLEY, E. (1997). Tigrinya root consonants and the OCP. Penn Working Papers in Linguistics, 4, 19-51.

CANTINEAU, J. (1946). Esquisse d'une phonologie de l'arabe classique. Bulletin de la société linguistique, 43, 93-140.

DELL, G. S. (1984). Representation of serial order in speech: Evidence from the repeated phoneme effect in speech errors. Journal of Experimental Psychology: Learning, Memory \& Cognition, 10, $222-233$.

DELL, G. S. (1990). Effects of frequency and vocabulary type on phonological speech errors. Language and Cognitive Processes, 5, 313-349.

DELL, G. S., REED, K. D., ADAMS, D. R., \& MEYER, A. S. (2000). Speech errors, phonotactic constraints, and implicit learning: A study of the role of experience in language production. Journal of Experimental Psychology: Learning, Memory, and Cognition, 26, 1355-1367.

DELL, G. S., \& REICH, P. A. (1980). Toward a unified theory of slips of the tongue. In V. A. Fromkin (Ed.), Errors in linguistic performance: Slips of the tongue, ear, pen, and hand (pp.273-286). New York: Academic Press.

Language and Speech 
ELMEDLAOUI, M. (1995). Géométrie des restrictions de cooccurrence de traits en sémitique et de berbère: Synchronie et diachronie. Revue canadienne de linguistique, 40, 39-79.

FRISCH, S. (1996). Similarity and frequency in phonology. PhD dissertation, Northwestern University.

FRISCH, S. (2000). Temporally organized lexical representations as phonological units. In M. B. Broe \& J. B. Pierrehumbert (Eds.), Acquisition and the lexicon: Papers in laboratory phonology V (pp. 283-298). Cambridge: Cambridge University Press.

FRISCH, S. (2004). Language processing and segmental OCP effects. In B. Hayes, R. Kirchner, \& D. Steriade (Eds.), Phonetically-based phonology (pp. 346-371). Cambridge: Cambridge University Press.

FRISCH, S., LARGE, N., ZAWAYDEH, B., \& PISONI, D. (2001). Emergent phonotactic generalizations in English and Arabic. In Joan Bybee \& Paul Hopper, (Eds.), Frequency and the emergence of linguistic structure (pp.159-179). Philadelphia: John Benjamins Publishing Company.

FRISCH, S., PIERREHUMBERT, J., \& BROE, M. (2004). Similarity avoidance and the OCP. Natural Language and Linguistic Theory, 22, 179-228.

FRISCH, S., \& WRIGHT, R. (2002). The phonetics of phonological speech errors: An acoustic analysis of slips of the tongue. Journal of Phonetics, 30, 139-162.

FRISCH, S., \& ZAWAYDEH, B. (2001). The psychological reality of OCP-Place in Arabic. Language, 77, 91-106.

FROMKIN, V. A. (1971). The non-anomalous nature of anomalous utterances. Language, 47, $27-52$.

GARCIA-ALBEA, J. E., DEL VISO, S., \& IGOA, J. M. (1989). Movement errors and levels of processing in sentence production. Journal of Psycholinguistic Research, 18, 145-161.

GOLDRICK, M. (2004). Phonological features and phonotactic constraints in speech production. Journal of Memory and Language, 51, 495-665.

GOLDSTEIN, L., POUPLIER, M., CHEN, L., SALTZMAN, E., \& BYRD, D. (2007). Dynamic action units slip in speech production errors. Cognition, 103, 386-412.

GORDON, J. (2002). Phonological neighborhood effects in aphasic speech errors: Spontaneous and structured contexts. Brain and Language, 82, 113-145.

GREENBERG, J. (1950). The patterning of root morphemes in Semitic. Word, 20, 157-177.

HANSSON, G. (2001a). The phonologization of production constraints: Evidence from consonant harmony. CLS 37: The main session. Papers from the 37th Meeting of the Chicago Linguistic Society, Vol. 1, 187-200.

HANSSON, G. (2001b). Theoretical and typological issues in consonant harmony. PhD dissertation, U.C. Berkeley.

HAYWARD, R. (1990). Notes on the Aari language. In R. Hayward (Ed.), Omotic language studies (pp. 425-493). London: School of Oriental and African Studies.

HAYWARD, K., \& HAYWARD, R. (1989). "Guttural”: Arguments for a new distinctive feature. Transactions of the Philological Society, 87, 179-193.

HYMAN, L. (1995). Nasal consonant harmony at a distance: The case of Yaka. Studies in African Linguistics, 24, 5-30.

KANE, T. L. (1990). Amharic-English Dictionary. Vols. 1 and 2. Wiesbaden: O. Harrassowitz.

KAWAHARA, S., ONO, H., \& SUDO, K. (2005). Consonant co-occurrence restrictions in Yamato Japanese. Japanese/ Korean Linguistics, 14, 27-38.

KEAN, M.-L. (1975). The theory of Markedness in generative grammar. PhD dissertation, Cambridge, MA: MIT.

KOHN, S. E., MELVOLD, J., \& SMITH, K. (1995). Consonant harmony as a compensatory mechanism in fluent aphasic speech. Cortex, 31, 747-756.

KOSKINEN, K. (1964). Kompatibilität in den dreikonsonantigen hebräischen Wurzeln. Zeitschrift der Deutschen Morgenländischen Gesellschaft, 114, 16-58. 
KUPIN, J. (1982). Tongue twisters as a source of information about speech production. Bloomington: IULC.

KURYLOWICZ, J. (1972). Studies in Semitic grammar and metrics. Warsaw: Polska Akademia Nauk.

LEBEN, W. (1973). Suprasegmental phonology. PhD dissertation, MIT.

LESLAU, W. (1952). The influence of Sidamo on the Ethiopic languages of Gurage. Language, 28, 63-81.

LESLAU, W. (1979). Etymological dictionary of Gurage (Ethiopic). Wiesbaden: Harrassowitz.

LEVITT, A. G., \& HEALEY, A. F. (1985). The roles of phoneme frequency, similarity, and availability in the experimental elicitation of speech errors. Journal of Memory and Language, 24, 717-733.

MacEACHERN, M. (1997) [1999]. Laryngeal co-occurrence restrictions. PhD dissertation, UCLA. [Published, New York: Garland, 1999].

MacKAY, D. G. (1970). Spoonerisms: The structure of errors in the serial order of speech. Neuropsychologia, 8, 323-350.

MacKAY, D. G. (1972). The structure of words and syllables: Evidence from errors in speech. Cognitive Psychology, 3, 210-227.

MacKAY, D. G. (1987). The organization of perception and action: A theory for language and other cognitive skills. New York: Springer.

McCARTHY, J. J. (1986). OCP Effects: Gemination and antigemination. Linguistic Inquiry, 17, 207-263.

McCARTHY, J. J. (1988). Feature geometry and dependency: A review. Phonetica, 43, 84-108.

McCARTHY, J. J. (1994). The phonetics and phonology of Semitic pharyngeals. In P. Keating (Ed.), Papers in laboratory phonology III. Phonological structure and phonetic form (pp. 191-283). Cambridge: Cambridge University Press.

McCLELLAND, J. L., \& RUMELHART, D. E. (1981). An interactive activation model of context effects in letter perception: Part 1. An account of the basic findings. Psychological Review, 88, 375- 407.

MESTER, R. A. (1986). Studies in tier structure. PhD dissertation, University of Massachusetts, Amherst.

MORETON, E. (2002). Phonological grammar in speech perception. $\mathrm{PhD}$ dissertation, University of Massachusetts, Amherst.

MORETON, E. (2004). Phonotactic constraints, frequency, and legality in English onset-cluster perception. Poster presented at the Acoustical Society of America meeting, New York City, May 24-28, 2004. Abstract in Journal of the Acoustical Society of America, 115 (5, Part 2), 2630.

MOTLEY, M., \& BAARS, B. J. (1975). Encoding sensitivities to phonological markedness and transition probability: Evidence from spoonerisms. Human Communication Research, 2, $351-361$.

MOWREY, R. A., \& MacKAY, I. R. A. (1990). Phonological primitives: Electromyographic speech error evidence. Journal of the Acoustical Society of America, 88, 1299-1312.

NOTEBOOM, S. G. (1967). Some regularities in phonemic speech errors. IPO Annual Progress Report II, 65-70.

O'BRYAN, T., \& ROSE, S. (2001). Segmental effects on (de)gemination in Western Gurage. Proceedings of the 27th Annual Meeting of the Berkeley Linguistics Society, Special Session on Afroasiatic Languages, 87-95.

OHALA, J., \& OHALA, M. (1986). Testing hypotheses regarding the psychological manifestation of morpheme structure constraints. In J. Ohala \& J. Jaeger, (Eds.), Experimental phonology (pp. 239-252). San Diego: Academic Press.

PADGETT, J. (1995). Stricture in feature geometry. CSLI Publications, Stanford University.

Language and Speech 
PARADIS, C., \& PRUNET, J.-F. (1993). On the validity of morpheme structure constraints. Canadian Journal of Linguistics, 38, 235-256.

PATER, J., \& COETZEE, A. (2005). Lexically specific constraints: Gradience, learnability, and perception. In Proceedings of the 3rd Seoul International Conference on Phonology (pp. 85-199). Seoul: The Phonology-Morphology Circle of Korea.

PETROS, D. P. (1996). Sonorant alternations in Chaha. In G. Hudson (Ed.), Essays on Gurage language and culture (pp.153-173). Wiesbaden: Harrassowitz Verlag.

PIERREHUMBERT, J. B. (1993). Dissimilarity in the Arabic verbal roots. Proceedings of the Northeast Linguistic Society, 23, 367-381.

POUPLIER, M. (2003). The dynamics of error. Proceedings of the 15th International Congress of Phonetic Sciences, 2245-2248.

POUPLIER, M. (2003). Units of phonological encoding: Empirical evidence. PhD dissertation, Yale University.

PRUNET, J.-F., BELAND, R., \& IDRISSI, A. (2000). The mental representation of Semitic words. Linguistic Inquiry, 31, 609-648.

REINER, E. (1966). A linguistic analysis of Akkadian. The Hague: Mouton.

ROMANI, C., \& CALABRESE, A. (1998). Syllabic constraints in the phonological errors of an aphasic patient. Brain and Language, 64, 83-121.

ROSE, S., \& WALKER, R. (2004). A typology of consonant agreement as correspondence. Language, 80, 475-531.

SCHWARTZ, M. F., SAFFRAN, E. M., BLOCH, D. E., \& DELL, G. S. (1994). Disordered speech production in aphasic and normal speakers. Brain and Language, 47, 52-88.

SHATTUCK-HUFNAGEL, S. (1988). Word-onset consonants in speech production planning. Speech Group Working Papers, 6, 181-200.

SHATTUCK-HUFNAGEL, S. (1992). The role of word structure in segmental serial ordering. Cognition, 42, 213-259.

SHATTUCK-HUFNAGEL, S., \& KLATT, D. (1979). The limited use of distinctive features and markedness in speech production. Journal of Verbal Learning and Verbal Behavior, 18, $41-55$.

STEMBERGER, J. P. (1982). The nature of segments in the lexicon: Evidence from speech errors. Lingua, 56, 235-259.

STEMBERGER, J. P. (1985a). An interactive activation model of language production. In A. W. Ellis, (Ed.), Progress in the psychology of language, Vol. 1 (pp. 143-186). London: Lawrence Erlbaum.

STEMBERGER, J. P. (1985b). The lexicon in a model of language production. New York: Garland. STEMBERGER, J. (1990). Wordshape errors in language production. Cognition, 35, 123-157.

STEMBERGER, J. P. (1991a). Apparent anti-frequency effects in language production: The addition bias and phonological underspecification. Journal of Memory and Language, 30, $161-185$.

STEMBERGER, J. P. (1991b). Radical underspecification in language production. Phonology, 8, $73-112$.

SUZUKI, K. (1998). A typological investigation of dissimilation. PhD dissertation, University of Arizona.

TOBIN, Y. (1990). Combinatory phonology of the Hebrew Triconsonantal (CCC) Root System. La linguistique, 26, 99-114.

TREIMAN, R., KESSLER, B., KNEWASSER, S., TINCOFF, R., \& BOWMAN, M. (2000). English speakers' sensitivity to phonotactic patterns. In M. B. Broe \& J. B. Pierrehumbert (Eds.), Papers in laboratory phonology V: Acquisition and the lexicon (pp. 269-282). Cambridge: Cambridge University Press.

VITEVITCH, M., \& LUCE, P. (1999). Probabilistic phonotactics and neighborhood activation in spoken word recognition. Journal of Memory and Language, 40, 374-408. 
VITEVITCH, M. S., LUCE, P. A., CHARLES-LUCE, J. \& KEMMERER, D. (1997). Phonotactics and syllable stress: implications for the processing of spoken nonsense words. Language and Speech, 40, 47-62.

VILJOEN, J. (1973). Manual for Ndonga. Part 1. Pretoria: University of South Africa.

VOUSDEN, J. I., BROWN, G. D. A., \& HARLEY, T. A. (2000). Serial control of phonology in speech production: A hierarchical model. Cognitive Psychology, 41, 101-175.

WALKER, R. (2007) Nasal and oral consonant similarity: Exploring parallels with long-distance nasal agreement. Language and Cognitive Processes, 22(7), 1-41.

WALKER, R., HACOPIAN, N., \& TAKI, M. (2002). Nasal consonant speech errors: Implications for "similarity" and nasal harmony at a distance. Collected Papers: First Pan-American/Iberian Meeting on Acoustics, Mexican Institute of Acoustics.

WEDEKIND, K. (1990). Glottalization constraints and Ethiopian counter-evidence. Folia Linguistica, 24, 94-127.

WEITZMAN, M. (1987). Statistical patterns in Hebrew and Arabic roots. Journal of the Royal Asiatic Society, 1, 15-22.

WILSHIRE, C. E. (1999). The "tongue twister" paradigm as a technique for studying phonological encoding. Language and Speech, 42, 57-82.

YIP, M. (1988). The obligatory contour principle and phonological rules: A loss of identity. Linguistic Inquiry, 19, 65-100.

YIP, M. (1989). Feature geometry and cooccurrence restrictions. Phonology, 6, 349-374.

ZURAW, K. (2000). Patterned exceptions in phonology. PhD dissertation, UCLA. 


\section{Appendix A: Test Stimuli}

Amharic: Test stimuli (Sets 1-4)

\begin{tabular}{|c|c|c|}
\hline $\begin{array}{c}\text { Set } \\
\text { (Frequency; } \\
\text { \# of pairs) }\end{array}$ & Set Members & $\begin{array}{l}\text { Twister Examples } \\
\text { (4 from } 1 \text { pair) }\end{array}$ \\
\hline $\begin{array}{l}\text { SET 1: } \\
\text { LC-VLESS (Low; 2) }\end{array}$ & $\mathrm{k}^{\prime} \mathrm{t} ; \mathrm{t}^{\prime} \mathrm{k}$ & 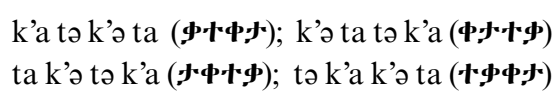 \\
\hline $\begin{array}{l}\text { SET 2: } \\
\text { POAC (Low; 11) }\end{array}$ & $\begin{array}{l}\text { s z; r l; t d; b f; k’ g; t’ d; } \\
\text { b m; m f; k g; n l; n r }\end{array}$ & $\begin{array}{l}\text { ba fə bə fa (М6.14.); bə fa fə ba (ח4.6.9) } \\
\text { fa bə fə ba (4.116.9); fə ba bə fa (6.914.) }\end{array}$ \\
\hline $\begin{array}{l}\text { SET } 3 \\
\text { DUAL (Low; 2) }\end{array}$ & $\mathrm{k}^{\prime} \mathrm{k} ; \mathrm{t}^{\prime} \mathrm{t}$ & 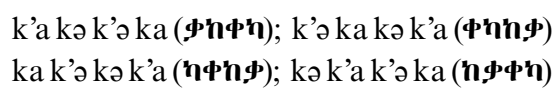 \\
\hline $\begin{array}{l}\text { SET } 4 \\
\text { LAR-OTHER (LOW; 1) }\end{array}$ & $\mathrm{k} \mathrm{d}$ & 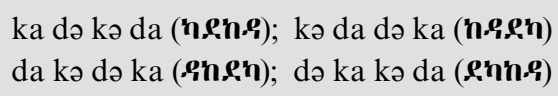 \\
\hline $\begin{array}{l}\text { SET 4: } \\
\text { LAR-OTHER } \\
\text { (LOW/HIGH; 3) }\end{array}$ & $\mathrm{k}^{\prime} \mathrm{d} ; \mathrm{tg} \mathrm{g} ; \mathrm{t}^{\prime} \mathrm{g}$ & 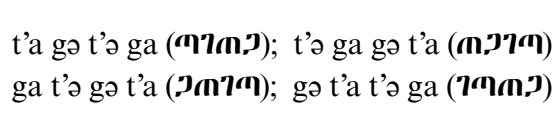 \\
\hline
\end{tabular}

Amharic: Control stimuli (Sets 5-6)

\begin{tabular}{|c|c|c|}
\hline $\begin{array}{c}\text { Set } \\
\text { (Frequency; } \\
\text { \# of pairs) }\end{array}$ & Set Members & $\begin{array}{l}\text { Twister Examples } \\
\text { (4 from } 1 \text { pair) }\end{array}$ \\
\hline $\begin{array}{l}\text { SET 5: } \\
\text { SIM (Low; 6) }\end{array}$ & $\mathrm{f} \mathrm{z} ; \mathrm{z} \mathrm{d} ; \mathrm{t} \mathrm{s} ; \mathrm{z} \mathrm{t} ; \mathrm{s} \mathrm{f} ; \mathrm{s} \mathrm{d}$ & 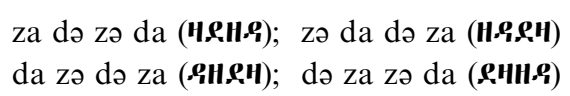 \\
\hline $\begin{array}{l}\text { SET 5: } \\
\text { SiM } \\
\text { (Low/HIGH; 6) }\end{array}$ & t's; t k; b g; k b; t b; n m & 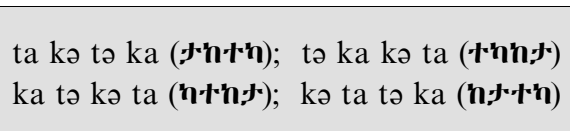 \\
\hline $\begin{array}{l}\text { SET 5: } \\
\text { SIM (HIGH; 5) }\end{array}$ & $\mathrm{k}^{\prime} \mathrm{t}^{\prime} ; \mathrm{d} \mathrm{g} ; \mathrm{t}^{\prime} \mathrm{b} ; \mathrm{d} \mathrm{b} ; \mathrm{k}^{\prime} \mathrm{b}$ & 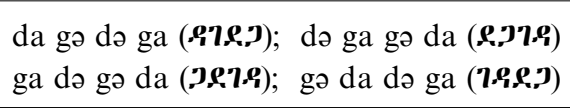 \\
\hline $\begin{array}{l}\text { SET 6: } \\
\text { DisSIM (Low; 4) }\end{array}$ & z k; z k’; n; f g & 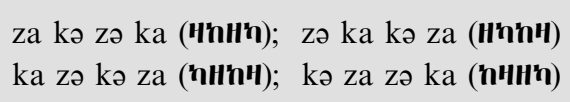 \\
\hline $\begin{array}{l}\text { SET 6: } \\
\text { DisSIM } \\
\text { (Low/High; 15) }\end{array}$ & $\begin{array}{l}\text { z g; t’ f; s k’; k’ f; m z; } \\
\text { f k; f t; m k; s g; k’ m; } \\
\text { f d; z r; b n; n k; n d }\end{array}$ & 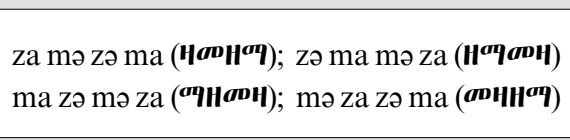 \\
\hline $\begin{array}{l}\text { Set 6: } \\
\text { Dissim } \\
\text { (High; 35) }\end{array}$ & 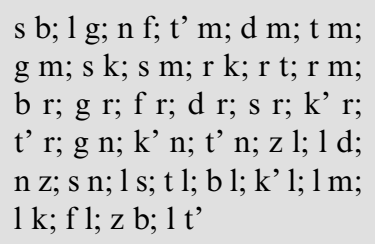 & 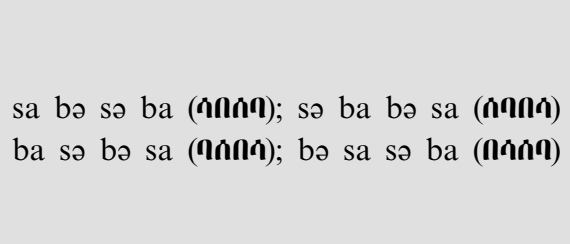 \\
\hline
\end{tabular}


Chaha: Test stimuli (Sets 1 - 4)

\begin{tabular}{|c|c|c|}
\hline $\begin{array}{c}\text { Set } \\
\text { (Frequency; } \\
\text { \# of pairs) }\end{array}$ & Set Members & $\begin{array}{l}\text { Twister Examples } \\
\text { (4 from } 1 \text { pair) }\end{array}$ \\
\hline $\begin{array}{l}\text { SET 1: } \\
\text { LC-VLESS (LOW; 2) }\end{array}$ & $k^{\prime} t ; t^{\prime} k$ & 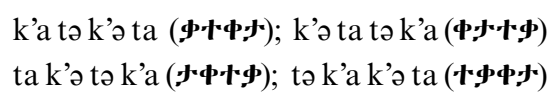 \\
\hline $\begin{array}{l}\text { SET 2: } \\
\text { POAC (Low; 4) }\end{array}$ & s z; m f; m b; b f & $\begin{array}{l}\text { ba fə bə fa (М6.14.); bə fa fə ba (M4.6.9) } \\
\text { fa bə fə ba (4.06.9); fə ba bə fa (6.9ก4.) }\end{array}$ \\
\hline $\begin{array}{l}\text { SET } 3 \\
\text { DUAL (Low; 6) }\end{array}$ & $\begin{array}{l}\mathrm{t} \text { d; } \mathrm{k}^{\prime} \mathrm{k} ; \mathrm{kg} ; \mathrm{t}^{\prime} \mathrm{d} ; \mathrm{t}^{\prime} \\
\mathrm{t} ; \mathrm{k}^{\prime} \mathrm{g}\end{array}$ & 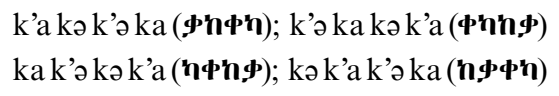 \\
\hline $\begin{array}{l}\text { SET } 4 \\
\text { LAR-OTHER (LOW; 3) }\end{array}$ & t g; t'g; k'd & 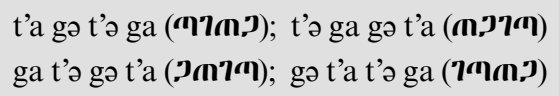 \\
\hline $\begin{array}{l}\text { SET 4: } \\
\text { SIM (LOW/HIGH; 1) }\end{array}$ & $\mathrm{k} \mathrm{d}$ & 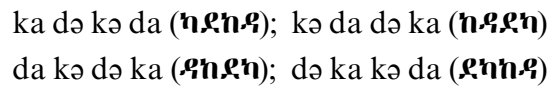 \\
\hline
\end{tabular}

Chaha: Control stimuli (Sets 5-6)

\begin{tabular}{|c|c|c|}
\hline $\begin{array}{c}\text { Set } \\
\text { (Frequency; } \\
\text { \# of pairs) }\end{array}$ & Set Members & $\begin{array}{l}\text { Twister Examples } \\
\text { (4 from } 1 \text { pair) }\end{array}$ \\
\hline $\begin{array}{l}\text { SET 5: } \\
\text { SIM (Low; 8) }\end{array}$ & $\begin{array}{l}\mathrm{z} \mathrm{d} ; \mathrm{z} \mathrm{t}^{\prime} ; \mathrm{z} \mathrm{t} ; \mathrm{g} \mathrm{b} ; \mathrm{f} \mathrm{z} ; \mathrm{t} \\
\mathrm{s} ; \mathrm{t} \mathrm{s} ; \mathrm{t} \mathrm{b}\end{array}$ & 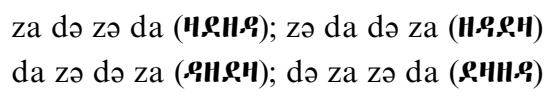 \\
\hline $\begin{array}{l}\text { SET 5: } \\
\text { SIM (Low/HIGH; 2) }\end{array}$ & $\mathrm{s} \mathrm{f} ; \mathrm{s} \mathrm{d}$ & 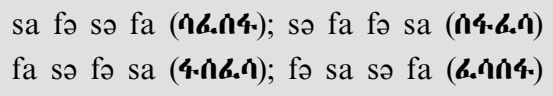 \\
\hline $\begin{array}{l}\text { SET 5: } \\
\text { SIM (HIGH; 7) }\end{array}$ & $\begin{array}{l}\mathrm{k}^{\prime} \mathrm{t}^{\prime} ; \mathrm{d} \mathrm{b} ; \mathrm{k} \mathrm{b} ; \mathrm{d} \mathrm{g} ; \mathrm{t} \mathrm{k} \\
\mathrm{k}^{\prime} \mathrm{b} ; \mathrm{t}^{\prime} \mathrm{b}\end{array}$ & 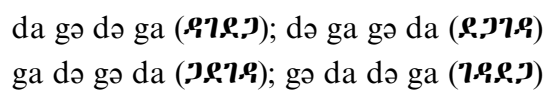 \\
\hline $\begin{array}{l}\text { SET 6: } \\
\text { DisSIM (Low; 3) }\end{array}$ & z k’; z k; k m & 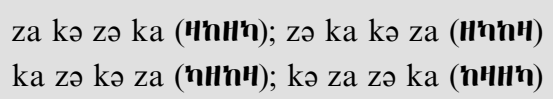 \\
\hline $\begin{array}{l}\text { SET 6: } \\
\text { DisSIM } \\
\text { (Low/HiGH; 7) }\end{array}$ & $\begin{array}{l}\text { b z; k’ m; k’ f; f t; } \\
\text { s m; m z;m g }\end{array}$ & 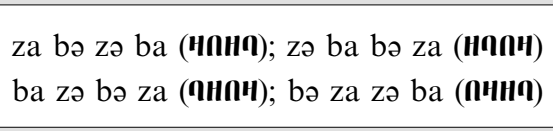 \\
\hline $\begin{array}{l}\text { SET 6: } \\
\text { DisSIM (HIGH; 27) }\end{array}$ & $\begin{array}{l}\text { b s; d f; f g; k f; t’ f; } \\
\text { g s; g z; k' s; k s; b r; } \\
\text { d m; d r; f n; f r; g n; } \\
\text { g r; k' n; t' n; k' r; r k; } \\
\text { m r; m t' m t; r s; } \\
\text { r t; r t’ r z }\end{array}$ & 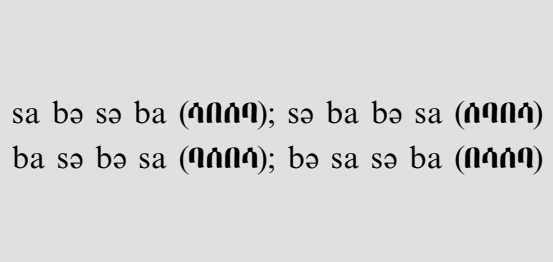 \\
\hline
\end{tabular}




\section{Appendix B: Error types}

Amharic - Classification of consonant combinations used in stimuli

\begin{tabular}{|c|c|c|c|}
\hline Sets & Freq & Tokens & Set Members \\
\hline Set 1 - LC-vless & Low & 4 & $\mathrm{k}^{\prime} \mathrm{t}, \mathrm{t}^{\prime} \mathrm{k}, \mathrm{t} \mathrm{k}, \mathrm{k} \mathrm{t}^{\prime}$ \\
\hline SET 2 - POAC & Low & 22 & $\begin{array}{l}\text { s z, r l, t d, b f, k' g, t' d, b m, m f, k g, n l, n r, } \\
\text { z s, l r, d t, f b, g k', d t', m b, f m, g k, l n, r n }\end{array}$ \\
\hline Set 3 - Dual & Low & 4 & $\mathrm{k}^{\prime} \mathrm{k}, \mathrm{t}^{\prime} \mathrm{t}, \mathrm{k} \mathrm{k}^{\prime}, \mathrm{t} \mathrm{t}^{\prime}$ \\
\hline \multirow{2}{*}{ Set 4 - LAR-OTHer } & Low & 5 & $\mathrm{k} \mathrm{d}, \mathrm{d} \mathrm{k}, \mathrm{k}^{\prime} \mathrm{d}, \mathrm{t} \mathrm{g}, \mathrm{t}^{\prime} \mathrm{g}$ \\
\hline & High & 3 & $\mathrm{~d} \mathrm{k}^{\prime}, \mathrm{g} \mathrm{t}, \mathrm{g} \mathrm{t}^{\prime}$ \\
\hline SET 5 - SiM & Low & 18 & $\begin{array}{l}\mathrm{f} z, \mathrm{z} \mathrm{d}, \mathrm{t} \mathrm{s}, \mathrm{zt}, \mathrm{s} f, \mathrm{~s} \mathrm{~d}, \mathrm{z} \text { f, d z, s t, t z, f s, d s, } \\
\text { t's, k t, b g, t b, k b, n m }\end{array}$ \\
\hline $\begin{array}{l}\text { (match on place } \\
\text { or manner) }\end{array}$ & High & 16 & $\begin{array}{l}k^{\prime} t^{\prime}, d \text { g, t' b, d b, k' b, t' k, g d, b t', b d, b k', } \\
\text { s t', t k, g b, b t, b k, m n }\end{array}$ \\
\hline Set 6 - Dissim & Low & 23 & 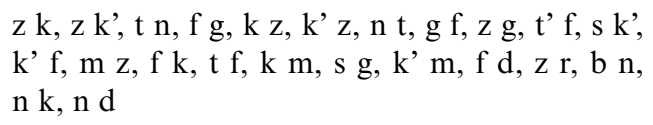 \\
\hline $\begin{array}{l}\text { (no match on place } \\
\text { or manner) }\end{array}$ & High & 85 & $\begin{array}{l}\text { s b, l g, n f, t' m, d m, t m, g m, s k, s m, r k, r t, } \\
\text { r m, b r, g r, f r, d r, s r, k' r, t' r, g n, k' n, t' n, } \\
\text { z l, l d, n z, s n, l s, t l, b l, k' l, l m, l k, f l, } \\
\text { z b, l t', b s, g l, f n, m t', m d, m t, m g, k s, m s, } \\
\text { k r, t r, m r, r b, r g, r f, r d, r s, r k', r t', n g, } \\
\text { n k', n t', l z, d l, z n, n s, s l, l t, l b, l k', m l, } \\
\text { k l, l f, b z, t' l, g z, f t', k' s, f k', z m, k f, f t, m k, } \\
\text { g s, m k', d f, r z, n b, k n, d n }\end{array}$ \\
\hline Total & & 180 & \\
\hline
\end{tabular}

Amharic - Grand total (226 errors in 10,080 productions)

\begin{tabular}{|l|c|c|c|c|c|c|c|}
\hline Total & $\mathbf{8 9}$ & $\mathbf{5 3}$ & $\mathbf{4 9}$ & $\mathbf{4}$ & $\mathbf{2 1}$ & $\mathbf{1 0}$ & $\mathbf{2 2 6}$ \\
\hline $1^{\text {st }}$ half & 30 & 27 & 15 & 2 & 6 & 4 & $\mathbf{8 4}$ \\
\hline $2^{\text {nd }}$ half & 59 & 26 & 34 & 2 & 15 & 6 & $\mathbf{1 4 2}$ \\
\hline
\end{tabular}


Set 1: LC-Vless (12 errors in 224 productions) - Low Frequency

\begin{tabular}{|l|c|c|c|c|c|c|c|} 
& Exchange & Substitution & $\begin{array}{c}\text { Feature } \\
\text { Change }\end{array}$ & $\begin{array}{c}\text { Feature } \\
\text { Exchange }\end{array}$ & $\begin{array}{c}\mathbf{1} / \mathbf{2} \\
\text { Exchange }\end{array}$ & $\begin{array}{c}\text { Double } \\
\text { Errors }\end{array}$ & Total \\
\hline Total & $\mathbf{2}$ & $\mathbf{3}$ & $\mathbf{5}$ & $\mathbf{1}$ & $\mathbf{1}$ & $\mathbf{0}$ & $\mathbf{1 2}$ \\
\hline $1^{\text {st }}$ half & 0 & 3 & 3 & 0 & 0 & 0 & 6 \\
\hline $2^{\text {nd }}$ half & 2 & 0 & 2 & 1 & 1 & 0 & 6 \\
\hline
\end{tabular}

Set 2: POAC (96 errors in 1232 productions) - Low Frequency

\begin{tabular}{|c|c|c|c|c|c|c|c|}
\hline & Exchange & Substitution & $\begin{array}{l}\text { Feature } \\
\text { Change }\end{array}$ & $\begin{array}{c}\text { Feature } \\
\text { Exchange }\end{array}$ & $\begin{array}{c}1 / 2 \\
\text { Exchange }\end{array}$ & $\begin{array}{l}\text { Double } \\
\text { Errors }\end{array}$ & Total \\
\hline Total & 40 & 19 & 21 & 0 & 10 & 6 & 96 \\
\hline $1^{\text {st }}$ half & 17 & 6 & 5 & 0 & 4 & $1 \quad(E S)$ & 33 \\
\hline $2^{\text {nd }}$ half & 23 & 13 & 16 & 0 & 6 & $\begin{array}{ll}2 & (\mathrm{ES}) \\
3 & (\mathrm{EFC}\end{array}$ & 63 \\
\hline
\end{tabular}

Set 3: Dual (34 errors in 224 productions) - Low Frequency

\begin{tabular}{|l|c|c|c|c|c|c|c|} 
& Exchange & Substitution & $\begin{array}{c}\text { Feature } \\
\text { Change }\end{array}$ & $\begin{array}{c}\text { Feature } \\
\text { Exchange }\end{array}$ & $\begin{array}{c}\mathbf{1} / \mathbf{2} \\
\text { Exchange }\end{array}$ & $\begin{array}{c}\text { Double } \\
\text { Errors }\end{array}$ & Total \\
\hline Total & $\mathbf{1 2}$ & $\mathbf{1 0}$ & $\mathbf{9}$ & $\mathbf{0}$ & $\mathbf{1}$ & $\mathbf{2}$ & $\mathbf{3 4}$ \\
\hline $1^{\text {st }}$ half & 6 & 8 & 1 & 0 & 0 & $2 \quad(\mathrm{ES})$ & 17 \\
\hline $2^{\text {nd }}$ half & 6 & 2 & 8 & 0 & 1 & 0 & 17 \\
\hline
\end{tabular}

Set 4: Lar-other ( 3 errors in 448 productions)

\begin{tabular}{|l|c|c|c|c|c|c|c|}
\hline $\begin{array}{l}\text { Sum } \\
\text { Totals }\end{array}$ & $\mathbf{1}$ & 0 & $\mathbf{2}$ & 0 & 0 & 0 & 3 \\
\hline $\begin{array}{l}\text { Low freq } \\
\text { Total }\end{array}$ & $\mathbf{1}$ & 0 & 0 & 0 & 0 & 0 & 1 \\
\hline $1^{\text {st }}$ half & 0 & 0 & 0 & 0 & 0 & 0 & 0 \\
\hline $2^{\text {nd }}$ half & 1 & 0 & 0 & 0 & 0 & 0 & 1 \\
\hline $\begin{array}{l}\text { High freq } \\
\text { Total }\end{array}$ & 0 & 0 & 2 & 0 & 0 & 0 & 2 \\
\hline $1^{\text {st }}$ half & 0 & 0 & 0 & 0 & 0 & 0 & 0 \\
\hline $2^{\text {nd }}$ half & 0 & 0 & 2 & 0 & 0 & 0 & 2 \\
\hline
\end{tabular}

Language and Speech 
Set 5: Similar Controls (19 errors in 1904 productions)

\begin{tabular}{|l|c|c|c|c|c|c|c|}
\hline $\begin{array}{l}\text { Sum } \\
\text { totals }\end{array}$ & $\mathbf{7}$ & $\mathbf{9}$ & $\mathbf{1}$ & $\mathbf{0}$ & $\mathbf{2}$ & $\mathbf{0}$ & $\mathbf{1 9}$ \\
\hline $\begin{array}{l}\text { Low freq: } \\
\text { Total }\end{array}$ & $\mathbf{1}$ & $\mathbf{5}$ & $\mathbf{0}$ & $\mathbf{0}$ & $\mathbf{2}$ & $\mathbf{0}$ & $\mathbf{8}$ \\
\hline $1^{\text {st }}$ half & 1 & 2 & 0 & 0 & 1 & 0 & 4 \\
\hline $2^{\text {nd }}$ half & 0 & 3 & 0 & 0 & 1 & 0 & 4 \\
\hline $\begin{array}{l}\text { High } \\
\text { freq: } \\
\text { Total }\end{array}$ & $\mathbf{6}$ & $\mathbf{4}$ & $\mathbf{1}$ & $\mathbf{0}$ & 0 & 0 & 11 \\
\hline $1^{\text {st }}$ half & 2 & 2 & 1 & 0 & 0 & 0 & 5 \\
\hline $2^{\text {nd }}$ half & 4 & 2 & 0 & 0 & 0 & 0 & 6 \\
\hline
\end{tabular}

Set 6: Dissimilar Controls (62 errors in 6048 productions)

\begin{tabular}{|l|c|c|c|c|c|c|c|} 
& Exchange & Substitution & $\begin{array}{c}\text { Feature } \\
\text { change }\end{array}$ & $\begin{array}{c}\text { Feature } \\
\text { Exchange }\end{array}$ & $\begin{array}{c}\mathbf{1} / 2 \\
\text { Exchange }\end{array}$ & $\begin{array}{c}\text { Double } \\
\text { Errors }\end{array}$ & Total \\
\hline $\begin{array}{l}\text { Sum } \\
\text { Total }\end{array}$ & $\mathbf{2 7}$ & $\mathbf{1 2}$ & $\mathbf{1 1}$ & $\mathbf{3}$ & $\mathbf{7}$ & $\mathbf{2}$ & $\mathbf{6 2}$ \\
\hline $\begin{array}{l}\text { Low freq: } \\
\text { Total }\end{array}$ & $\mathbf{6}$ & $\mathbf{3}$ & $\mathbf{3}$ & $\mathbf{3}$ & $\mathbf{3}$ & $\mathbf{0}$ & $\mathbf{1 8}$ \\
\hline $1^{\text {st }}$ half & 2 & 2 & 2 & 2 & 1 & 0 & 9 \\
\hline $2^{\text {nd }}$ half & 4 & 1 & 1 & 1 & 2 & 0 & 9 \\
\hline $\begin{array}{l}\text { High freq: } \\
\text { Total }\end{array}$ & $\mathbf{2 1}$ & $\mathbf{9}$ & $\mathbf{8}$ & $\mathbf{0}$ & $\mathbf{4}$ & $\mathbf{2}$ & $\mathbf{4 4}$ \\
\hline $1^{\text {st }}$ half & 2 & 4 & 3 & 0 & 1 & 1 (SS) & 11 \\
\hline $2^{\text {nd }}$ half & 19 & 5 & 5 & 0 & 3 & 1 (ES) & 33 \\
\hline
\end{tabular}


Chaha - Classification of consonant combinations used in stimuli

\begin{tabular}{|c|c|c|c|}
\hline Sets & Freq & Twisters & Set Members \\
\hline SET 1 - LC-VLESS & Low & 4 & $\mathrm{k}^{\prime} \mathrm{t}, \mathrm{t}^{\prime} \mathrm{k}, \mathrm{t} \mathrm{k}, \mathrm{k} \mathrm{t}^{\prime}$ \\
\hline SET 2 - POAC & Low & 8 & $\mathrm{~s} \mathrm{z}, \mathrm{b} \mathrm{f}, \mathrm{b} \mathrm{m}, \mathrm{m} \mathrm{f}, \mathrm{z} \mathrm{s}, \mathrm{f} \mathrm{b}, \mathrm{m} \mathrm{b}, \mathrm{fm}$ \\
\hline Set 3 - DuAl & Low & 12 & $\begin{array}{l}\mathrm{k}^{\prime} \mathrm{k}, \mathrm{t}^{\prime} \mathrm{t}, \mathrm{k}^{\prime} \mathrm{g}, \mathrm{t}^{\prime} \mathrm{d}, \mathrm{kg}, \mathrm{t} \mathrm{d}, \mathrm{k} \mathrm{k}, \mathrm{t} \mathrm{t}^{\prime}, \mathrm{g} \mathrm{k}, \mathrm{d} \mathrm{t}^{\prime}, \\
\mathrm{g} \mathrm{k}, \mathrm{d} \mathrm{t}\end{array}$ \\
\hline \multirow{2}{*}{ SET 4 - LAR-OTHER } & Low & 7 & $\mathrm{t}^{\prime} \mathrm{g}, \mathrm{k} \mathrm{d}^{\prime}, \mathrm{t} \mathrm{g}, \mathrm{g} \mathrm{t}, \mathrm{d} \mathrm{k}, \mathrm{g} \mathrm{t}, \mathrm{d} \mathrm{k}$ \\
\hline & High & 1 & $\mathrm{k} \mathrm{d}$ \\
\hline SET 5 - SiM & Low & 18 & $\begin{array}{l}\mathrm{z} \text { d, z t', t z, g b, f z, t's, s t, t b, d z, t' z, z t, } \\
\text { b g, z f, s t', t s, b t, f s, d s }\end{array}$ \\
\hline $\begin{array}{l}\text { (match on place } \\
\text { or manner) }\end{array}$ & High & 16 & $\begin{array}{l}k^{\prime} t^{\prime}, k \mathrm{t}, \mathrm{d} \mathrm{b}, \mathrm{k} \mathrm{b}, \mathrm{d} \mathrm{g}, \mathrm{k}^{\prime} \mathrm{b}, \mathrm{t}^{\prime} \mathrm{b}, \mathrm{t}^{\prime} \mathrm{k}^{\prime}, \mathrm{k} \mathrm{t}, \mathrm{b} \text { d, } \\
\text { b k, g d, b k', b t', s f, s d }\end{array}$ \\
\hline SET 6 - Dissim & Low & 13 & $\begin{array}{l}\text { z k', z k, k m, k' z, k z, m k, b z, m k', k’ f, f t, } \\
\text { s m, m z, m g }\end{array}$ \\
\hline $\begin{array}{l}\text { (no match on place } \\
\text { or manner) }\end{array}$ & High & 61 & $\begin{array}{l}\text { b s, d f, f g, f k, f t', g s, g z, k' s, k s, b r, d m, } \\
\text { d r, f n, f r, g n, g r, k' n, t' n, k' r, k r, m r, m t', } \\
\text { m t, s r, r t, r t', z z, s b, f d, g f, k f, t' f, s g, z g, } \\
\text { s k', s k, r b, m d, r d, n f, r f, n g, r g, n k', n t', } \\
\text { r k', r k, r m, t' m, t m, r s, tr, t'r, z r, z b, k' m, } \\
\text { f k', t f, m s, z m, g m }\end{array}$ \\
\hline Total & & 140 & \\
\hline
\end{tabular}

Chaha - Grand total (267 errors out of 9520 productions)

\begin{tabular}{|l|c|c|c|c|c|c|c|c|} 
& Exchange & Substitution & $\begin{array}{c}\text { Feature } \\
\text { Change }\end{array}$ & $\begin{array}{c}\mathbf{1} / \mathbf{2} \\
\text { Exchange }\end{array}$ & $\begin{array}{c}\text { Feature } \\
\text { Exchange }\end{array}$ & Insertion & $\begin{array}{c}\text { Double } \\
\text { Errors }\end{array}$ & $\begin{array}{c}\text { Total } \\
\text { Errors }\end{array}$ \\
\hline Total & $\mathbf{1 2 6}$ & $\mathbf{6 2}$ & $\mathbf{6 1}$ & $\mathbf{8}$ & $\mathbf{1}$ & $\mathbf{1}$ & $\mathbf{8}$ & $\mathbf{2 6 7}$ \\
\hline $1^{\text {st }}$ half & 28 & 46 & 26 & 1 & 0 & 1 & 3 & $\mathbf{1 0 5}$ \\
\hline $2^{\text {nd }}$ half & 98 & 16 & 35 & 7 & 1 & 0 & 5 & $\mathbf{1 6 2}$ \\
\hline
\end{tabular}


Set1: LC-Vless (17 errors in 272 productions) - Low Frequency

\begin{tabular}{|l|c|c|c|c|c|c|c|c|} 
& Exchange & Substitution & $\begin{array}{c}\text { Feature } \\
\text { Change }\end{array}$ & $\begin{array}{c}1 / 2 \\
\text { Exchange }\end{array}$ & $\begin{array}{c}\text { Feature } \\
\text { Exchange }\end{array}$ & Insertion & $\begin{array}{c}\text { Double } \\
\text { Errors }\end{array}$ & $\begin{array}{c}\text { Total } \\
\text { Errors }\end{array}$ \\
\hline Total & $\mathbf{2}$ & $\mathbf{6}$ & $\mathbf{8}$ & $\mathbf{0}$ & $\mathbf{1}$ & $\mathbf{0}$ & $\mathbf{0}$ & $\mathbf{1 7}$ \\
\hline $1^{\text {st }}$ half & 0 & 5 & 4 & 0 & 0 & 0 & 0 & $\mathbf{9}$ \\
\hline $2^{\text {nd }}$ half & 2 & 1 & 4 & 0 & 1 & 0 & 0 & 8 \\
\hline
\end{tabular}

Set 2: POAC (35 errors in 544 productions) - Low Frequency

\begin{tabular}{|l|c|c|c|c|c|c|c|c|} 
& Exchange & Substitution & $\begin{array}{c}\text { Feature } \\
\text { Change }\end{array}$ & $\begin{array}{c}\mathbf{1} / \mathbf{2} \\
\text { Exchange }\end{array}$ & $\begin{array}{c}\text { Feature } \\
\text { Exchange }\end{array}$ & Insertion & $\begin{array}{c}\text { Double } \\
\text { Errors }\end{array}$ & $\begin{array}{c}\text { Total } \\
\text { Errors }\end{array}$ \\
\hline Total & $\mathbf{2 4}$ & $\mathbf{1}$ & $\mathbf{8}$ & $\mathbf{2}$ & $\mathbf{0}$ & $\mathbf{0}$ & $\mathbf{0}$ & $\mathbf{3 5}$ \\
\hline $1^{\text {st }}$ half & 7 & 1 & 5 & 1 & 0 & 0 & 0 & $\mathbf{1 4}$ \\
\hline $2^{\text {nd }}$ half & 17 & 0 & 3 & 1 & 0 & 0 & 0 & $\mathbf{2 1}$ \\
\hline
\end{tabular}

Set 3: Dual (105 errors in 816 productions) - Low Frequency

\begin{tabular}{|l|c|c|c|c|c|c|c|c|} 
& Exchange & Substitution & $\begin{array}{c}\text { Feature } \\
\text { Change }\end{array}$ & $\begin{array}{c}1 / 2 \\
\text { Exchange }\end{array}$ & $\begin{array}{c}\text { Feature } \\
\text { Exchange }\end{array}$ & Insertion & $\begin{array}{c}\text { Double } \\
\text { Errors }\end{array}$ & $\begin{array}{c}\text { Total } \\
\text { Errors }\end{array}$ \\
\hline Total & 60 & $\mathbf{1 2}$ & $\mathbf{2 6}$ & $\mathbf{2}$ & $\mathbf{0}$ & $\mathbf{0}$ & $\mathbf{5}$ & $\mathbf{1 0 5}$ \\
\hline $1^{\text {st }}$ half & 15 & 6 & 8 & 0 & 0 & 0 & $1(\mathrm{EFC})$ & $\mathbf{3 0}$ \\
\hline $2^{\text {nd }}$ half & 45 & 6 & 18 & 2 & 0 & 0 & $4(3 \mathrm{ES}$ & $\mathbf{7 5}$ \\
\hline
\end{tabular}

Set 4: Lar-other (14 errors in 544 productions)

\begin{tabular}{|l|c|c|c|c|c|c|c|c|} 
& Exchange & Substitution & $\begin{array}{c}\text { Feature } \\
\text { Change }\end{array}$ & $\begin{array}{c}1 / 2 \\
\text { Exchange }\end{array}$ & $\begin{array}{c}\text { Feature } \\
\text { Exchange }\end{array}$ & Insertion & $\begin{array}{c}\text { Double } \\
\text { Errors }\end{array}$ & $\begin{array}{c}\text { Total } \\
\text { Errors }\end{array}$ \\
\hline $\begin{array}{l}\text { Sum } \\
\text { Totals }\end{array}$ & 1 & 3 & 9 & 0 & 0 & 0 & 1 & 14 \\
\hline $\begin{array}{l}\text { Low freq: } \\
\text { Total }\end{array}$ & 1 & 3 & 6 & 0 & 0 & 0 & 1 & 11 \\
\hline $1^{\text {st }}$ half & 0 & 2 & 2 & 0 & 0 & 0 & 0 & 4 \\
\hline $2^{\text {nd }}$ half & 1 & 1 & 4 & 0 & 0 & 0 & $1(\mathrm{ES})$ & $\mathbf{7}$ \\
\hline $\begin{array}{l}\text { High freq: } \\
\text { Total }\end{array}$ & 0 & 0 & 3 & 0 & 0 & 0 & 0 & 3 \\
\hline $1^{\text {st }}$ half & 0 & 0 & 1 & 0 & 0 & 0 & 0 & 1 \\
\hline $2^{\text {nd }}$ half & 0 & 0 & 2 & 0 & 0 & 0 & 0 & 2 \\
\hline
\end{tabular}


Set 5: Similar Controls (48 errors in 2312 productions)

\begin{tabular}{|l|c|c|c|c|c|c|c|c|} 
& Exchange & Substitution & $\begin{array}{c}\text { Feature } \\
\text { Change }\end{array}$ & $\begin{array}{c}1 / 2 \\
\text { Exchange }\end{array}$ & $\begin{array}{c}\text { Feature } \\
\text { Exchange }\end{array}$ & Insertion & $\begin{array}{c}\text { Double } \\
\text { Errors }\end{array}$ & $\begin{array}{c}\text { Total } \\
\text { Errors }\end{array}$ \\
\hline $\begin{array}{l}\text { Sum } \\
\text { Totals }\end{array}$ & 20 & 16 & $\mathbf{7}$ & 3 & 0 & 0 & 2 & 48 \\
\hline $\begin{array}{l}\text { Low freq: } \\
\text { Total }\end{array}$ & 14 & 6 & 2 & 3 & 0 & 0 & 1 & 26 \\
\hline $1^{\text {st }}$ half & 2 & 5 & 1 & 0 & 0 & 0 & $1(\mathrm{EFC})$ & 9 \\
\hline $2^{\text {nd }}$ half & 12 & 1 & 1 & 3 & 0 & 0 & 0 & 17 \\
\hline $\begin{array}{l}\text { High freq: } \\
\text { Total }\end{array}$ & $\mathbf{6}$ & 10 & $\mathbf{5}$ & 0 & 0 & 0 & 1 & $\mathbf{2 2}$ \\
\hline $1^{\text {st }}$ half & 0 & 8 & 4 & 0 & 0 & 0 & $1(\mathrm{ES})$ & 13 \\
\hline $2^{\text {nd }}$ half & 6 & 2 & 1 & 0 & 0 & 0 & 0 & 9 \\
\hline
\end{tabular}

Set 6: Dissimilar Controls (48 errors in 5032 productions)

\begin{tabular}{|l|c|c|c|c|c|c|c|c|} 
& Exchange & Substitution & $\begin{array}{c}\text { Feature } \\
\text { Change }\end{array}$ & $\begin{array}{c}1 / 2 \\
\text { Exchange }\end{array}$ & $\begin{array}{c}\text { Feature } \\
\text { Exchange }\end{array}$ & Insertion & $\begin{array}{c}\text { Double } \\
\text { Errors }\end{array}$ & $\begin{array}{c}\text { Total } \\
\text { Errors }\end{array}$ \\
\hline Sum Total & 19 & 24 & 3 & 1 & 0 & 1 & 0 & 48 \\
\hline $\begin{array}{l}\text { Low freq: } \\
\text { Total }\end{array}$ & 3 & 1 & 1 & 0 & 0 & 0 & 0 & 5 \\
\hline $1^{\text {st }}$ half & 0 & 1 & 1 & 0 & 0 & 0 & 0 & 2 \\
\hline $2^{\text {nd } h a l f ~}$ & 3 & 0 & 0 & 0 & 0 & 0 & 0 & 3 \\
\hline $\begin{array}{l}\text { High freq: } \\
\text { Total }\end{array}$ & 16 & 23 & 2 & 1 & 0 & 1 & 0 & 43 \\
\hline $1^{\text {st }}$ half & 4 & 18 & 0 & 0 & 0 & 1 & 0 & 23 \\
\hline $2^{\text {nd }}$ half & 12 & 5 & 2 & 1 & 0 & 0 & 0 & 20 \\
\hline
\end{tabular}




\section{Appendix C:}

\section{Specific error types per consonant - Amharic}

Exchange errors: 89 errors +9 exchange from double errors $=98$

\begin{tabular}{|c|c|c|c|c|c|c|c|c|c|c|c|c|c|c|c|}
$\mathbf{C 1}$ & $\mathbf{C 2}$ & $\mathbf{n}$ & $\mathbf{l}$ & $\mathbf{m}$ & $\mathbf{b}$ & $\mathbf{f}$ & $\mathbf{t}$ & $\mathbf{d}$ & $\mathbf{t}$ & $\mathbf{k}$ & $\mathbf{g}$ & $\mathbf{k}$ & $\mathbf{s}$ & $\mathbf{z}$ & Total \\
\hline $\mathbf{r}$ & & 0 & 0 & 0 & 0 & 0 & 0 & 1 & 0 & 0 & 0 & 0 & 0 & 0 & $\mathbf{1}$ \\
\hline $\mathbf{n}$ & 0 & & 1 & 0 & 0 & 0 & 0 & 1 & 0 & 0 & 0 & 0 & 1 & 0 & $\mathbf{3}$ \\
\hline $\mathbf{I}$ & 1 & 2 & & 0 & 0 & 1 & 0 & 1 & 1 & 0 & 0 & 0 & 2 & 0 & $\mathbf{8}$ \\
\hline $\mathbf{m}$ & 0 & 0 & 1 & & 1 & 2 & 0 & 1 & 0 & 0 & 0 & 0 & 1 & 0 & $\mathbf{6}$ \\
\hline $\mathbf{b}$ & 0 & 0 & 0 & 4 & & 1 & 0 & 1 & 2 & 0 & 0 & 0 & 0 & 2 & 10 \\
\hline $\mathbf{f}$ & 1 & 0 & 0 & 0 & 0 & & 0 & 0 & 1 & 1 & 0 & 0 & 0 & 0 & $\mathbf{3}$ \\
\hline $\mathbf{t}$ & 0 & 0 & 1 & 0 & 1 & 0 & & 1 & 3 & 0 & 0 & 1 & 0 & 0 & $\mathbf{7}$ \\
\hline $\mathbf{d}$ & 1 & 0 & 1 & 0 & 0 & 0 & 0 & & 0 & 0 & 0 & 0 & 0 & 0 & $\mathbf{2}$ \\
\hline $\mathbf{t}^{\prime}$ & 0 & 0 & 1 & 0 & 2 & 0 & 2 & 0 & & 0 & 1 & 0 & 0 & 0 & $\mathbf{6}$ \\
\hline $\mathbf{k}$ & 1 & 0 & 0 & 0 & 0 & 0 & 0 & 0 & 0 & & 5 & 6 & 0 & 0 & $\mathbf{1 2}$ \\
\hline $\mathbf{g}$ & 0 & 0 & 0 & 0 & 0 & 0 & 0 & 0 & 0 & 10 & & 6 & 0 & 0 & $\mathbf{1 6}$ \\
\hline $\mathbf{k}$ & 0 & 0 & 0 & 0 & 0 & 2 & 1 & 0 & 0 & 3 & 3 & & 0 & 0 & $\mathbf{9}$ \\
\hline $\mathbf{s}$ & 0 & 0 & 0 & 0 & 0 & 0 & 0 & 0 & 1 & 0 & 0 & 1 & & 5 & $\mathbf{7}$ \\
\hline $\mathbf{z}$ & 1 & 1 & 0 & 0 & 2 & 0 & 0 & 0 & 0 & 0 & 0 & 0 & 4 & & $\mathbf{8}$ \\
\hline Total & $\mathbf{5}$ & $\mathbf{3}$ & $\mathbf{4}$ & $\mathbf{5}$ & $\mathbf{6}$ & $\mathbf{6}$ & $\mathbf{3}$ & $\mathbf{6}$ & $\mathbf{8}$ & $\mathbf{1 4}$ & $\mathbf{9}$ & $\mathbf{1 4}$ & $\mathbf{8}$ & $\mathbf{7}$ & $\mathbf{9 8}$ \\
\hline
\end{tabular}

Substitution errors : $53+7$ substitutions from double errors $=60$

\begin{tabular}{|c|c|c|c|c|c|c|c|c|c|c|c|c|c|c|c|c|c|c|}
\hline $\begin{array}{c}\text { Error } \\
\text { Target }\end{array}$ & $\mathbf{r}$ & $\mathbf{n}$ & $\mathbf{l}$ & $\mathbf{m}$ & $\mathbf{b}$ & $\mathbf{f}$ & $\mathbf{t}$ & $\mathbf{d}$ & $\mathbf{t}$ & $\mathbf{k}$ & $\mathbf{g}$ & $\mathbf{k}$ & $\mathbf{s}$ & $\mathbf{z}$ & $\mathbf{w}$ & $\mathbf{p}$ & $\mathbf{f}$ & $\mathbf{T}$ \\
\hline $\mathbf{r}$ & & 0 & 1 & 0 & 0 & 3 & 1 & 0 & 0 & 0 & 1 & 0 & 0 & 1 & 0 & 0 & 0 & $\mathbf{7}$ \\
\hline $\mathbf{n}$ & 0 & & 0 & 0 & 2 & 0 & 0 & 0 & 0 & 1 & 1 & 0 & 0 & 0 & 0 & 0 & 0 & $\mathbf{4}$ \\
\hline $\mathbf{l}$ & 0 & 0 & & 0 & 0 & 0 & 1 & 0 & 0 & 0 & 0 & 0 & 7 & 0 & 0 & 0 & 0 & $\mathbf{8}$ \\
\hline $\mathbf{m}$ & 0 & 0 & 0 & & 2 & 0 & 2 & 0 & 0 & 0 & 0 & 0 & 0 & 0 & 0 & 0 & 0 & $\mathbf{4}$ \\
\hline $\mathbf{b}$ & 0 & 0 & 0 & 3 & & 0 & 0 & 0 & 0 & 0 & 0 & 0 & 0 & 0 & 1 & 0 & 0 & $\mathbf{4}$ \\
\hline $\mathbf{f}$ & 0 & 0 & 0 & 0 & 0 & & 0 & 0 & 0 & 0 & 0 & 0 & 0 & 0 & 0 & 0 & 1 & $\mathbf{1}$ \\
\hline $\mathbf{t}$ & 0 & 0 & 0 & 0 & 1 & & & 0 & 0 & 0 & 0 & 0 & 1 & 0 & 0 & 1 & 0 & 3 \\
\hline $\mathbf{d}$ & 0 & 0 & 0 & 0 & 0 & 0 & 1 & & 0 & 0 & 0 & 0 & 0 & 0 & 0 & 0 & 0 & $\mathbf{1}$ \\
\hline $\mathbf{t}$ & 0 & 0 & 0 & 0 & 1 & 0 & 0 & 0 & & 0 & 0 & 0 & 0 & 0 & 0 & 0 & 0 & $\mathbf{1}$ \\
\hline $\mathbf{k}$ & 0 & 1 & 0 & 0 & 0 & 0 & 1 & 0 & 0 & & 10 & 2 & 0 & 0 & 0 & 0 & 0 & $\mathbf{1 4}$ \\
\hline $\mathbf{g}$ & 0 & 0 & 0 & 0 & 0 & 0 & 0 & 0 & 0 & 5 & & 2 & 0 & 0 & 0 & 0 & 0 & $\mathbf{7}$ \\
\hline $\mathbf{k}$ & 0 & 0 & 0 & 0 & 0 & 0 & 1 & 0 & 1 & 0 & 1 & & 0 & 0 & 0 & 0 & 0 & $\mathbf{3}$ \\
\hline $\mathbf{s}$ & 0 & 0 & 1 & 0 & 0 & 0 & 0 & 0 & 0 & 0 & 0 & 0 & & 1 & 0 & 0 & 0 & $\mathbf{2}$ \\
\hline $\mathbf{z}$ & 1 & 0 & 0 & 0 & 0 & 0 & 0 & 0 & 0 & 0 & 0 & 0 & 0 & & 0 & 0 & 0 & $\mathbf{1}$ \\
\hline Total & $\mathbf{1}$ & $\mathbf{1}$ & $\mathbf{2}$ & $\mathbf{3}$ & $\mathbf{6}$ & $\mathbf{3}$ & $\mathbf{7}$ & $\mathbf{0}$ & $\mathbf{1}$ & $\mathbf{6}$ & $\mathbf{1 3}$ & $\mathbf{4}$ & $\mathbf{8}$ & $\mathbf{2}$ & $\mathbf{1}$ & $\mathbf{1}$ & $\mathbf{1}$ & $\mathbf{6 0}$ \\
\hline
\end{tabular}


Feature change errors: $49+3$ feature changes from double errors $=52$

\begin{tabular}{|c|c|c|c|c|c|c|c|c|c|c|c|c|c|c|c|}
\hline Error & $\mathbf{r}$ & $\mathbf{n}$ & $\mathbf{l}$ & $\mathbf{m}$ & $\mathbf{b}$ & $\mathbf{f}$ & $\mathbf{t}$ & $\mathbf{d}$ & $\mathbf{t}$ & $\mathbf{k}$ & $\mathbf{g}$ & $\mathbf{k}$ & $\mathbf{s}$ & $\mathbf{z}$ & Total \\
Target & $\mathbf{r}$ & & & & & & & & & & & & \\
\hline $\mathbf{r}$ & & 0 & 0 & 0 & 0 & 0 & 0 & 0 & 1 & 0 & 0 & 0 & 0 & 0 & $\mathbf{1}$ \\
\hline $\mathbf{n}$ & 1 & & 2 & 0 & 0 & 0 & 0 & 0 & 0 & 0 & 0 & 0 & 0 & 0 & 3 \\
\hline $\mathbf{l}$ & 0 & 0 & & 0 & 1 & 0 & 0 & 0 & 0 & 0 & 0 & 0 & 1 & 0 & $\mathbf{2}$ \\
\hline $\mathbf{m}$ & 0 & 0 & 0 & & 1 & 0 & 0 & 0 & 0 & 0 & 0 & 0 & 0 & 0 & 1 \\
\hline $\mathbf{b}$ & 0 & 0 & 0 & 1 & & 0 & 0 & 0 & 0 & 0 & 0 & 0 & 0 & 0 & 1 \\
\hline $\mathbf{f}$ & 0 & 0 & 0 & 0 & 0 & & 0 & 0 & 0 & 0 & 0 & 0 & 0 & 0 & 0 \\
\hline $\mathbf{t}$ & 0 & 0 & 0 & 0 & 0 & 0 & & 0 & 6 & 1 & 0 & 0 & 0 & 0 & $\mathbf{7}$ \\
\hline $\mathbf{d}$ & 0 & 0 & 0 & 0 & 0 & 0 & 1 & & 0 & 0 & 0 & 0 & 0 & 0 & $\mathbf{1}$ \\
\hline $\mathbf{t}$ & 1 & 0 & 0 & 0 & 1 & 0 & 0 & 0 & & 0 & 0 & 0 & 0 & 0 & $\mathbf{2}$ \\
\hline $\mathbf{k}$ & 0 & 0 & 0 & 0 & 0 & 1 & 1 & 0 & 0 & & 7 & 5 & 0 & 0 & $\mathbf{1 4}$ \\
\hline $\mathbf{g}$ & 0 & 0 & 0 & 0 & 0 & 0 & 0 & 0 & 0 & 7 & & 1 & 0 & 0 & $\mathbf{8}$ \\
\hline $\mathbf{k}$ & 0 & 0 & 0 & 0 & 0 & 0 & 0 & 2 & 0 & 3 & 5 & & 0 & 0 & $\mathbf{1 0}$ \\
\hline $\mathbf{s}$ & 0 & 0 & 0 & 0 & 0 & 0 & 0 & 0 & 0 & 0 & 0 & 0 & & 2 & $\mathbf{2}$ \\
\hline $\mathbf{z}$ & 0 & 0 & 0 & 0 & 0 & 0 & 0 & 0 & 0 & 0 & 0 & 0 & 0 & & 0 \\
\hline Total & $\mathbf{2}$ & $\mathbf{0}$ & $\mathbf{2}$ & $\mathbf{1}$ & $\mathbf{3}$ & $\mathbf{1}$ & $\mathbf{2}$ & $\mathbf{2}$ & $\mathbf{7}$ & $\mathbf{1 1}$ & $\mathbf{1 2}$ & $\mathbf{6}$ & $\mathbf{1}$ & $\mathbf{2}$ & $\mathbf{5 2}$ \\
\hline
\end{tabular}

1/2 Exchange errors: 21 errors

\begin{tabular}{|c|c|c|c|c|c|c|c|c|c|c|c|c|c|c|c|}
\hline $\mathrm{Cl}^{\mathrm{C} 2}$ & $\mathbf{r}$ & $\mathbf{n}$ & 1 & $\mathbf{m}$ & b & $\mathbf{f}$ & $\mathbf{t}$ & d & $\mathbf{t}^{\prime}$ & $\mathbf{k}$ & g & $k^{\prime}$ & $\mathbf{S}$ & $\mathbf{z}$ & Total \\
\hline $\mathbf{r}$ & & 0 & 0 & 0 & 0 & 0 & 0 & 0 & 0 & 0 & 0 & 0 & 0 & 0 & $\mathbf{0}$ \\
\hline $\mathbf{n}$ & 1 & & 0 & 0 & 0 & 0 & 0 & 0 & 0 & 0 & 0 & 0 & 0 & 0 & 1 \\
\hline 1 & 1 & 0 & & 0 & 0 & 0 & 0 & 0 & 0 & 0 & 0 & 0 & 0 & 0 & 1 \\
\hline m & 0 & 0 & 0 & & 0 & 2 & 1 & 0 & 0 & 0 & 0 & 0 & 0 & 0 & 3 \\
\hline $\mathbf{b}$ & 0 & 0 & 0 & 0 & & 0 & 0 & 0 & 0 & 0 & 0 & 0 & 0 & 1 & 1 \\
\hline f & 0 & 0 & 0 & 0 & 0 & & 0 & 0 & 0 & 1 & 0 & 0 & 0 & 0 & 1 \\
\hline $\mathbf{t}$ & 0 & 0 & 0 & 0 & 0 & 0 & & 1 & 0 & 0 & 0 & 0 & 1 & 0 & 2 \\
\hline d & 0 & 0 & 0 & 0 & 0 & 0 & 0 & & 0 & 0 & 0 & 0 & 0 & 0 & 0 \\
\hline $\mathbf{t}^{\prime}$ & 0 & 1 & 0 & 0 & 0 & 0 & 0 & 2 & & 0 & 0 & 0 & 0 & 0 & 3 \\
\hline $\mathbf{k}$ & 0 & 0 & 0 & 0 & 0 & 0 & 0 & 0 & 0 & & 0 & 0 & 0 & 0 & 0 \\
\hline $\mathbf{g}$ & 0 & 0 & 0 & 0 & 0 & 0 & 0 & 0 & 0 & 0 & & 2 & 0 & 0 & 2 \\
\hline $\mathbf{k}^{\prime}$ & 1 & 0 & 0 & 1 & 0 & 0 & 1 & 0 & 0 & 1 & 0 & & 0 & 0 & 4 \\
\hline $\mathbf{s}$ & 0 & 0 & 0 & 0 & 0 & 0 & 1 & 0 & 0 & 0 & 0 & 0 & & 1 & 2 \\
\hline $\mathbf{z}$ & 0 & 0 & 0 & 0 & 0 & 0 & 0 & 0 & 0 & 0 & 1 & 0 & 0 & & 1 \\
\hline Total & 3 & 1 & 0 & 1 & 0 & 2 & 3 & 3 & 0 & 2 & 1 & 2 & 1 & 2 & 21 \\
\hline
\end{tabular}

Feature exchange errors (4):

$\mathbf{k ~ t ' ~} \rightarrow$ k' t; s g s g $\rightarrow$ z k z k; z k' $\rightarrow$ s g

Language and Speech 


\section{Appendix C:}

Specific error type per consonant - Chaha

Exchange errors: $126+7$ from double errors $=133$

\begin{tabular}{|c|c|c|c|c|c|c|c|c|c|c|c|c|c|c|}
\hline Earget & $\mathbf{r}$ & n & m & b & f & $\mathbf{t}$ & d & $\mathbf{t}^{\prime}$ & k & $\mathbf{g}$ & $\mathrm{k}^{\prime}$ & $\mathbf{s}$ & $\mathbf{z}$ & Total \\
\hline $\mathbf{r}$ & & 0 & 0 & 0 & 1 & 1 & 0 & 0 & 0 & 0 & 0 & 0 & 0 & 2 \\
\hline $\mathrm{n}$ & 0 & & 0 & 0 & 0 & 0 & 0 & 0 & 0 & 1 & 0 & 0 & 0 & 1 \\
\hline $\mathbf{m}$ & 0 & 0 & & 6 & 2 & 0 & 0 & 0 & 0 & 0 & 0 & 0 & 0 & 8 \\
\hline b & 0 & 0 & 2 & & 0 & 0 & 2 & 2 & 1 & 0 & 0 & 1 & 0 & 8 \\
\hline f & 1 & 0 & 1 & 0 & & 0 & 0 & 0 & 0 & 0 & 0 & 1 & 0 & 3 \\
\hline $\mathbf{t}$ & 2 & 0 & 0 & 0 & 0 & & 3 & 2 & 0 & 1 & 2 & 1 & 1 & 12 \\
\hline d & 0 & 0 & 1 & 0 & 0 & 3 & & 8 & 0 & 0 & 0 & 1 & 1 & 14 \\
\hline $\mathbf{t}^{\prime}$ & 0 & 1 & 0 & 1 & 0 & 2 & 5 & & 0 & 0 & 0 & 0 & 2 & 11 \\
\hline $\mathbf{k}$ & 0 & 0 & 0 & 0 & 0 & 0 & 0 & 0 & & 5 & 4 & 3 & 1 & 13 \\
\hline g & 0 & 1 & 0 & 0 & 0 & 0 & 0 & 1 & 12 & & 13 & 0 & 0 & 27 \\
\hline $\mathbf{k}^{\prime}$ & 1 & 0 & 0 & 0 & 1 & 0 & 0 & 1 & 2 & 5 & & 0 & 0 & 10 \\
\hline $\mathbf{s}$ & 0 & 0 & 0 & 1 & 0 & 0 & 0 & 4 & 1 & 0 & 0 & & 8 & 14 \\
\hline $\mathbf{z}$ & 0 & 0 & 0 & 0 & 0 & 0 & 0 & 4 & 1 & 0 & 0 & 5 & & 10 \\
\hline Total & 4 & 2 & 4 & 8 & 4 & 6 & 10 & 22 & 17 & 12 & 19 & 12 & 13 & 133 \\
\hline
\end{tabular}

Substitution errors: 62 errors +6 from double errors $=68$

\begin{tabular}{|c|c|c|c|c|c|c|c|c|c|c|c|c|c|c|c|c|}
\hline Error & $\mathbf{r}$ & n & m & b & f & $t$ & d & $\mathbf{t}^{\prime}$ & k & g & $k^{\prime}$ & $\mathbf{S}$ & $\mathbf{z}$ & $\mathbf{x}$ & I & Total \\
\hline $\mathbf{r}$ & & 0 & 0 & 0 & 1 & 0 & 0 & 0 & 0 & 0 & 0 & 0 & 0 & 0 & 0 & 1 \\
\hline $\mathbf{n}$ & 0 & & 0 & 0 & 0 & 2 & 0 & 0 & 0 & 1 & 0 & 0 & 0 & 0 & 0 & 3 \\
\hline $\mathbf{m}$ & 0 & 0 & & 0 & 0 & 0 & 0 & 0 & 0 & 0 & 0 & 0 & 0 & 0 & 0 & 0 \\
\hline b & 0 & 0 & 0 & & 0 & 0 & 0 & 0 & 0 & 0 & 0 & 0 & 0 & 0 & 0 & 0 \\
\hline f & 0 & 0 & 0 & 0 & & 0 & 0 & 0 & 0 & 0 & 0 & 0 & 0 & 1 & 0 & 1 \\
\hline $\mathbf{t}$ & 0 & 1 & 0 & 1 & 0 & & 1 & 0 & 0 & 1 & 0 & 0 & 0 & 0 & 0 & 4 \\
\hline d & 1 & 0 & 0 & 0 & 0 & 2 & & 0 & 0 & 0 & 0 & 0 & 0 & 0 & 0 & 3 \\
\hline $\mathbf{t}^{\prime}$ & 0 & 0 & 1 & 1 & 0 & 1 & 2 & & 0 & 0 & 1 & 2 & 0 & 0 & 0 & 8 \\
\hline $\mathbf{k}$ & 0 & 0 & 0 & 1 & 0 & 0 & 0 & 0 & & 9 & 0 & 0 & 0 & 9 & 0 & 19 \\
\hline g & 0 & 0 & 0 & 0 & 0 & 1 & 0 & 0 & 8 & & 3 & 0 & 1 & 0 & 0 & 13 \\
\hline$k^{\prime}$ & 0 & 0 & 0 & 0 & 0 & 0 & 0 & 1 & 1 & 1 & & 0 & 0 & 0 & 0 & 3 \\
\hline $\mathbf{S}$ & 0 & 0 & 0 & 0 & 0 & 1 & 0 & 0 & 1 & 0 & 0 & & 5 & 0 & 1 & 8 \\
\hline $\mathbf{Z}$ & 0 & 2 & 0 & 0 & 0 & 1 & 1 & 0 & 0 & 0 & 0 & 1 & & 0 & 0 & 5 \\
\hline Total & 1 & 3 & 1 & 3 & 1 & 8 & 4 & 1 & 10 & 12 & 4 & 3 & 6 & 10 & 1 & 68 \\
\hline
\end{tabular}


Feature change errors: 62 errors +2 from double errors $=64$

\begin{tabular}{|c|c|c|c|c|c|c|c|c|c|c|c|c|c|c|c|}
\hline Error & $\mathbf{r}$ & $\mathbf{n}$ & $\mathbf{m}$ & $\mathbf{b}$ & $\mathbf{f}$ & $\mathbf{t}$ & $\mathbf{d}$ & $\mathbf{t}$ & $\mathbf{k}$ & $\mathbf{g}$ & $\mathbf{k}$ & $\mathbf{s}$ & $\mathbf{z}$ & $\mathbf{p}$ & Total \\
Target & & & & & & & & & & & & \\
\hline $\mathbf{r}$ & & 0 & 0 & 0 & 1 & 0 & 0 & 0 & 0 & 0 & 0 & 0 & 1 & 0 & $\mathbf{2}$ \\
\hline $\mathbf{n}$ & 0 & & 0 & 0 & 0 & 0 & 0 & 0 & 0 & 0 & 0 & 0 & 0 & 0 & 0 \\
\hline $\mathbf{m}$ & 0 & 0 & & 0 & 2 & 0 & 0 & 0 & 0 & 0 & 0 & 0 & 0 & 0 & $\mathbf{2}$ \\
\hline $\mathbf{b}$ & 0 & 0 & 1 & & 0 & 0 & 0 & 0 & 0 & 0 & 0 & 0 & 0 & 1 & $\mathbf{2}$ \\
\hline $\mathbf{f}$ & 0 & 0 & 0 & 0 & & 0 & 0 & 0 & 0 & 0 & 0 & 0 & 0 & 0 & $\mathbf{0}$ \\
\hline $\mathbf{t}$ & 0 & 0 & 0 & 0 & 0 & & 0 & 11 & 2 & 0 & 0 & 0 & 1 & 0 & $\mathbf{1 4}$ \\
\hline $\mathbf{d}$ & 0 & 0 & 0 & 0 & 0 & 2 & & 0 & 0 & 1 & 0 & 0 & 0 & 0 & $\mathbf{3}$ \\
\hline $\mathbf{t}$ & 0 & 0 & 0 & 0 & 0 & 1 & 1 & & 0 & 0 & 0 & 0 & 0 & 0 & $\mathbf{2}$ \\
\hline $\mathbf{k}$ & 0 & 0 & 0 & 0 & 0 & 0 & 1 & 0 & & 7 & 9 & 0 & 0 & 0 & $\mathbf{1 7}$ \\
\hline $\mathbf{g}$ & 0 & 0 & 0 & 0 & 0 & 0 & 0 & 0 & 6 & & 1 & 0 & 0 & 0 & $\mathbf{7}$ \\
\hline $\mathbf{k}$ & 0 & 0 & 0 & 0 & 0 & 0 & 0 & 0 & 2 & 6 & & 0 & 0 & 0 & $\mathbf{8}$ \\
\hline $\mathbf{s}$ & 0 & 0 & 0 & 0 & 0 & 0 & 0 & 0 & 0 & 0 & 0 & & 5 & 0 & $\mathbf{5}$ \\
\hline $\mathbf{z}$ & 0 & 0 & 0 & 0 & 0 & 0 & 1 & 0 & 0 & 0 & 0 & 1 & & 0 & $\mathbf{2}$ \\
\hline Total & $\mathbf{0}$ & $\mathbf{0}$ & $\mathbf{1}$ & $\mathbf{0}$ & $\mathbf{3}$ & $\mathbf{3}$ & $\mathbf{3}$ & $\mathbf{1 1}$ & $\mathbf{1 0}$ & $\mathbf{1 4}$ & $\mathbf{1 0}$ & $\mathbf{1}$ & $\mathbf{7}$ & $\mathbf{1}$ & $\mathbf{6 4}$ \\
\hline
\end{tabular}

$1 / 2$ exchange errors: 8 errors

\begin{tabular}{|c|c|c|c|c|c|c|c|c|c|c|c|c|c|c|}
\hline Error & $\mathbf{r}$ & $\mathbf{n}$ & $\mathbf{m}$ & $\mathbf{b}$ & $\mathbf{f}$ & $\mathbf{t}$ & $\mathbf{d}$ & $\mathbf{t}$ & $\mathbf{k}$ & $\mathbf{g}$ & $\mathbf{k}$ & $\mathbf{s}$ & $\mathbf{z}$ & Total \\
\hline Target & & & & & & & & & & & & & \\
\hline $\mathbf{r}$ & & 0 & 0 & 0 & 0 & 0 & 0 & 0 & 0 & 0 & 0 & 0 & 0 & 0 \\
\hline $\mathbf{n}$ & 0 & & 0 & 0 & 0 & 0 & 0 & 0 & 0 & 0 & 0 & 0 & 0 & 0 \\
\hline $\mathbf{m}$ & 0 & 0 & & 1 & 0 & 0 & 0 & 1 & 0 & 0 & 0 & 0 & 0 & $\mathbf{2}$ \\
\hline $\mathbf{b}$ & 0 & 0 & 0 & & 0 & 0 & 0 & 0 & 0 & 0 & 0 & 0 & 0 & 0 \\
\hline $\mathbf{f}$ & 0 & 0 & 0 & 0 & & 0 & 0 & 0 & 0 & 0 & 0 & 0 & 0 & 0 \\
\hline $\mathbf{t}$ & 0 & 0 & 0 & 0 & 0 & & 0 & 2 & 0 & 0 & 0 & 0 & 0 & $\mathbf{2}$ \\
\hline $\mathbf{d}$ & 0 & 0 & 0 & 0 & 0 & 0 & & 0 & 0 & 0 & 0 & 0 & 1 & $\mathbf{1}$ \\
\hline $\mathbf{t}$ & 0 & 0 & 0 & 0 & 0 & 0 & 0 & & 0 & 0 & 0 & 0 & 0 & 0 \\
\hline $\mathbf{k}$ & 0 & 0 & 0 & 0 & 0 & 0 & 0 & 0 & & 0 & 0 & 0 & 0 & 0 \\
\hline $\mathbf{g}$ & 0 & 0 & 0 & 0 & 0 & 0 & 0 & 0 & 0 & & 0 & 0 & 0 & 0 \\
\hline $\mathbf{k}$ & 0 & 0 & 0 & 0 & 0 & 0 & 0 & 0 & 0 & 0 & & 0 & 0 & 0 \\
\hline $\mathbf{s}$ & 0 & 0 & 0 & 0 & 0 & 0 & 1 & 1 & 0 & 0 & 0 & & 0 & $\mathbf{2}$ \\
\hline $\mathbf{z}$ & 0 & 0 & 0 & 0 & 0 & 0 & 0 & 0 & 0 & 0 & 0 & 1 & & $\mathbf{1}$ \\
\hline Total & $\mathbf{0}$ & $\mathbf{0}$ & $\mathbf{0}$ & $\mathbf{1}$ & $\mathbf{0}$ & $\mathbf{0}$ & $\mathbf{1}$ & $\mathbf{4}$ & $\mathbf{0}$ & $\mathbf{0}$ & $\mathbf{0}$ & $\mathbf{1}$ & $\mathbf{1}$ & $\mathbf{8}$ \\
\hline
\end{tabular}

Feature exchange error (1): $k^{\prime} t \rightarrow t^{\prime} k$

Insertion (1): s b $\rightarrow$ s b s (sa bə ba sə $\rightarrow$ sə bəs ba sə)

Language and Speech 


\section{Appendix D: Similarity calculations}

SPMV Rankings - Amharic

\begin{tabular}{|c|c|c|c|l|l|l|l|l|l|l|l|l|l|l|l|l|l|l|}
\hline \multicolumn{10}{|c|}{ Amharic featural difference matrix } \\
\hline C & Place & Son & Manner & Laryngeal & r & I & n & m & b & f & t' & t & d & k' & k & g & s & z \\
\hline r & alv & son & rhotic & voiced & 0 & & & & & & & & & & & & & \\
\hline 1 & alv & son & lateral & voiced & 1 & 0 & & & & & & & & & & & & \\
\hline n & alv & son & nasal & voiced & 1 & 1 & 0 & & & & & & & & & & & \\
\hline m & labial & son & nasal & voiced & 2 & 2 & 1 & 0 & & & & & & & & & & \\
\hline b & labial & obs & stop & voiced & 3 & 3 & 3 & 2 & 0 & & & & & & & & & \\
\hline f & labial & obs & fric & voiceless & 4 & 4 & 4 & 3 & 2 & 0 & & & & & & & & \\
\hline t' & alv & obs & stop & vless ejective & 3 & 3 & 3 & 4 & 2 & 3 & 0 & & & & & & & \\
\hline t & alv & obs & stop & voiceless & 3 & 3 & 3 & 4 & 2 & 2 & 1 & 0 & & & & & & \\
\hline d & alv & obs & stop & voiced & 2 & 2 & 2 & 3 & 1 & 3 & 1 & 1 & 0 & & & & & \\
\hline k' & velar & obs & stop & vless ejective & 4 & 4 & 4 & 4 & 2 & 3 & 1 & 2 & 2 & 0 & & & & \\
\hline k & velar & obs & stop & voiceless & 4 & 4 & 4 & 4 & 2 & 2 & 2 & 1 & 2 & 1 & 0 & & & \\
\hline g & velar & obs & stop & voiced & 3 & 3 & 3 & 3 & 1 & 3 & 2 & 2 & 1 & 1 & 1 & 0 & & \\
\hline s & alv & obs & fric & voiceless & 3 & 3 & 3 & 4 & 3 & 1 & 2 & 1 & 2 & 2 & 2 & 3 & 0 & \\
\hline z & alv & obs & fric & voiced & 2 & 2 & 2 & 3 & 2 & 2 & 2 & 2 & 1 & 3 & 3 & 2 & 1 & 0 \\
\hline
\end{tabular}

Sets of Consonants (SIM = 1 or 2 ; DISSIM = 3 or 4$)$

\begin{tabular}{|c|c|c|c|}
\hline Set & Freq & Pairs & \\
\hline SET 2 & Low & 20 & $\begin{array}{l}\text { s z, z s, r l, l r, t d, d t, b f, f b, k' g, g k', t' d, d t', b m, m b, k g, } \\
\text { g k, n 1, 1 n, n r, r n (m f, f m pair removed) }\end{array}$ \\
\hline \multirow{2}{*}{$\begin{array}{l}\text { SET } 5 \\
\text { SIM }\end{array}$} & Low & 23 & 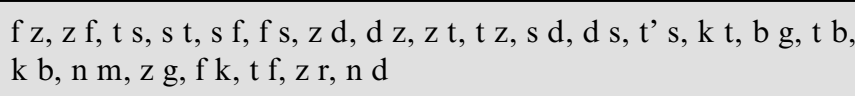 \\
\hline & $\mathrm{HIGH}$ & 37 & 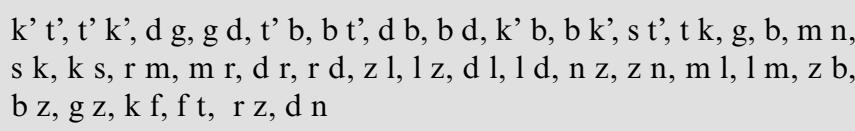 \\
\hline \multirow[b]{2}{*}{$\begin{array}{l}\text { SET } 6 \\
\text { DisSIM }\end{array}$} & Low & 18 & $\begin{array}{l}\text { z k, z k', t n, n t, g f, f g, t' f, s k', k' f, m z, k m, s g, k' m, f d, } \\
\text { b n, n k }\end{array}$ \\
\hline & $\mathrm{HIGH}$ & 64 & 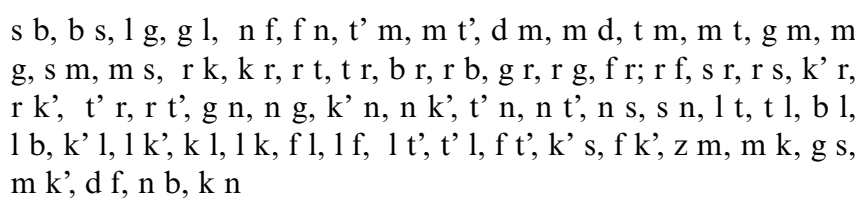 \\
\hline
\end{tabular}


Error rate per set

\begin{tabular}{|l|c|c|c|c|} 
& Errors & Correct Tokens & Total Tokens & Error rate \\
\hline Set 1 & 12 & 212 & 224 & .0536 \\
\hline Set 2 & $89 *$ & 1031 & 1120 & .0795 \\
\hline Set 3 & 36 & 188 & 224 & .1607 \\
\hline Set 4 Low freq. & 1 & 279 & 280 & .0357 \\
\hline Set 4 High freq. & 2 & 166 & 168 & .0119 \\
\hline Set 5 Low freq. & 15 & 1273 & 1288 & .0116 \\
\hline Set 5 High freq. & 26 & 2046 & 2072 & .0125 \\
\hline Set 6 Low freq. & 11 & 997 & 1008 & .0109 \\
\hline Set 6 High freq. & 30 & 3554 & 3584 & .0084 \\
\hline Total & $\mathbf{2 2 2}$ & $\mathbf{9 7 4 6}$ & $\mathbf{9 9 6 8}$ &. $\mathbf{0 2 2 3}$ \\
\hline
\end{tabular}

* 2 errors from $[\mathrm{m} \mathrm{f}]$ and [ $\mathrm{f}$ ] pairs removed

Fisher's Exact tests

Similarity hypothesis

Set 5 (Low Frequency) versus Set 6 (Low Frequency) $-p=1$

Set 5 (High Frequency) versus Set 6 (High Frequency) $-p=.0933$

Frequency hypothesis

Set 5 (Low Frequency) versus Set 5 (High Frequency) $-p=.8729$

Set 6 (Low Frequency) versus Set 6 (High Frequency) $-p=.4495$ 


\section{SPMV Rankings - Chaha}

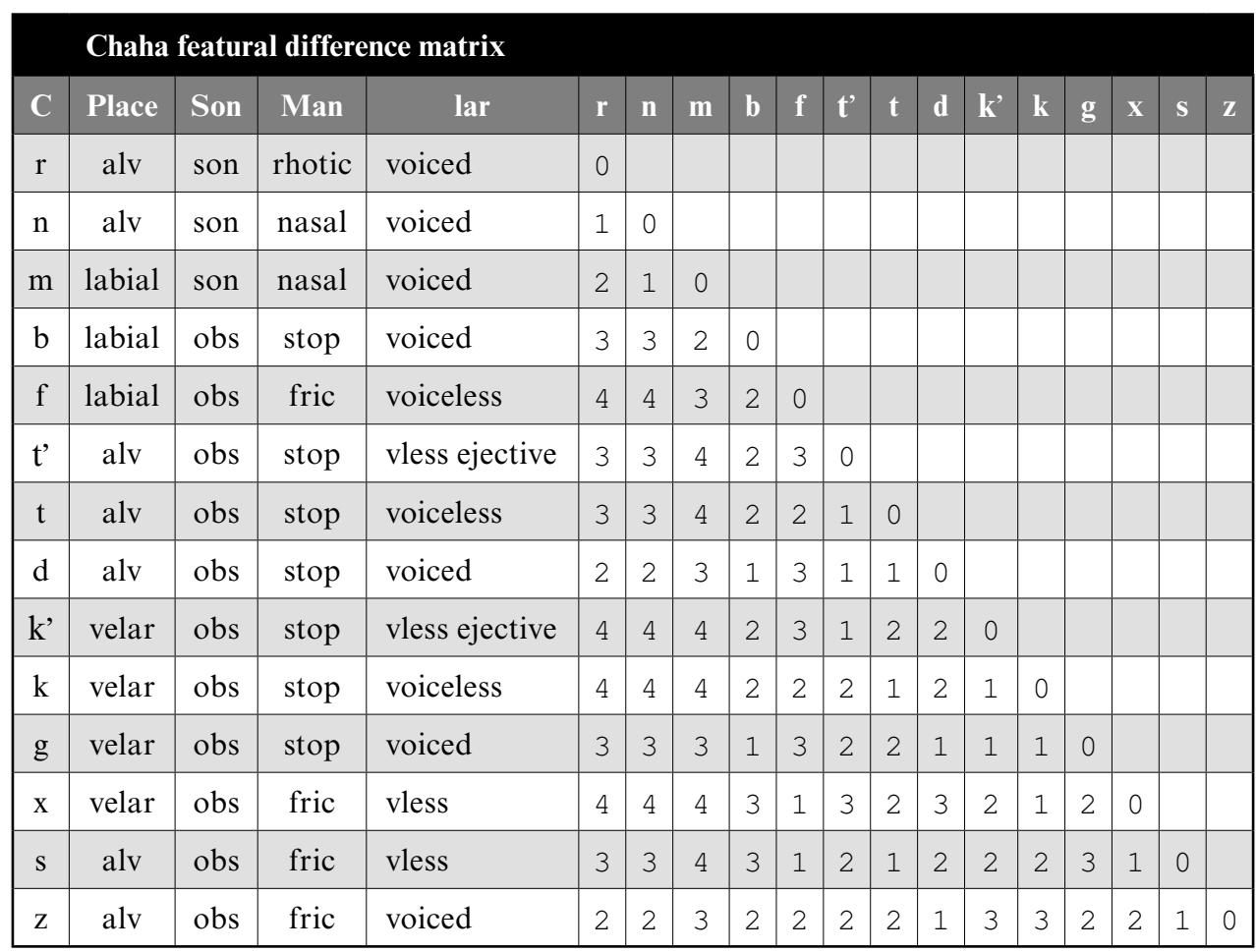

Sets of Consonants (SIM $=1$ or 2 ; DISSIM $=3$ or 4$)$

\begin{tabular}{|c|c|c|c|}
\hline Set & Freq & Pairs & \\
\hline SET 2 & Low & 6 & $\mathrm{~s} \mathrm{z}, \mathrm{b} f, \mathrm{~b} \mathrm{~m}, \mathrm{z} \mathrm{s}, \mathrm{f} \mathrm{b}, \mathrm{m} \mathrm{b}$ ( $\mathrm{m} \mathrm{f}, \mathrm{f} \mathrm{m}$ pair removed) \\
\hline \multirow{2}{*}{$\begin{array}{l}\text { SET } 5 \\
\text { SIM }\end{array}$} & Low & 20 & 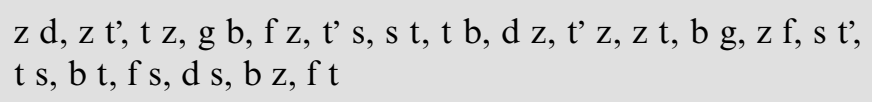 \\
\hline & $\mathrm{HIGH}$ & 32 & $\begin{array}{l}k^{\prime} \text { t', k t, d b, k b, d g, k' b, t' b; t' k', k t, b d, b k, g d, b k', } \\
\text { b t', s f, s d, z b, f k, k f, t f, g z, z g, k' s, s k', k s, s k, d r, } \\
\text { r d, m r, r m, r z, z r }\end{array}$ \\
\hline \multirow[b]{2}{*}{$\begin{array}{l}\text { SET } 6 \\
\text { DisSIM }\end{array}$} & Low & 11 & $\mathrm{z}^{\prime}, \mathrm{z} \mathrm{k}, \mathrm{k} \mathrm{m}, \mathrm{k}^{\prime} \mathrm{z}, \mathrm{k} \mathrm{z}, \mathrm{m} \mathrm{k}, \mathrm{m}$ k', k’ f, s m, m z, m g \\
\hline & $\mathrm{HIGH}$ & 45 & $\begin{array}{l}\text { b s, d f, f g, f t', g s, b r, d m, f n, f r, g n, g r, k' n, t' n, k' r, } \\
\text { k r, m t', m t, s r, r t, r t', s b, f d, g f, t' f, s g, r b, m d, n f, } \\
\text { r f, n g, r g, n k, n t', r k, r k, t' m, t m, r s, t r, t' r, k' m, } \\
\text { f k', m s, z m, g m }\end{array}$ \\
\hline
\end{tabular}


Error rate per set

\begin{tabular}{|l|c|c|c|c|} 
& Errors & Correct Tokens & Total Tokens & Error rate \\
\hline Set $\mathbf{1}$ & 17 & 255 & 272 & .0625 \\
\hline Set 2 & $30 *$ & 378 & 408 & .0735 \\
\hline Set 3 & 105 & 711 & 816 & .1287 \\
\hline Set 4 Low freq. & 11 & 465 & 476 & .0231 \\
\hline Set 4 High freq. & 3 & 65 & 68 & .0441 \\
\hline Set 5 Low freq. & 26 & 1334 & 1360 & .0191 \\
\hline Set 5 High freq. & 40 & 2136 & 2176 & .0184 \\
\hline Set 6 Low freq. & 5 & 743 & 748 & .0067 \\
\hline Set 6 High freq. & 25 & 3035 & 3060 & .0082 \\
\hline \multicolumn{1}{r|}{ Total } & $\mathbf{2 6 2}$ & $\mathbf{9 1 2 2}$ & $\mathbf{9 3 8 4}$ & .0279 \\
\hline
\end{tabular}

* 5 errors from $[\mathrm{m} \mathrm{f}$ ] and [ $\mathrm{fm}$ ] pairs removed

Fisher's Exact tests

Similarity hypothesis

Set 5 (Low Frequency) versus Set 6 (Low Frequency) $-p=.0230$

Set 5 (High Frequency) versus Set 6 (High Frequency) $-p=.0014$

Set 5 (combined) vs. Set 6 (combined) $-p<.0001$.

Frequency hypothesis

Set 5 (Low Frequency) versus Set 5 (High Frequency) $-p=.8987$

Set 6 (Low Frequency) versus Set 6 (High Frequency) $-p=.8200$ 


\section{SFC Rankings - Amharic}

Shared Feature Class Similarity Matrix - Amharic

\begin{tabular}{|c|c|c|c|c|c|c|c|c|c|c|c|c|c|c|}
$\mathbf{C}$ & $\mathbf{r}$ & $\mathbf{l}$ & $\mathbf{n}$ & $\mathbf{m}$ & $\mathbf{b}$ & $\mathbf{f}$ & $\mathbf{t}$ & $\mathbf{t}$ & $\mathbf{d}$ & $\mathbf{k}$ & $\mathbf{k}$ & $\mathbf{g}$ & $\mathbf{s}$ & $\mathbf{z}$ \\
\hline $\mathbf{r}$ & 1 & & & & & & & & & & & & & \\
\hline $\mathbf{l}$ & .857 & 1 & & & & & & & & & & & & \\
\hline $\mathbf{n}$ & .441 & .389 & 1 & & & & & & & & & & & \\
\hline $\mathbf{m}$ & .222 & .200 & .393 & 1 & & & & & & & & & & \\
\hline $\mathbf{b}$ & .175 & .154 & .235 & .480 & 1 & & & & & & & & & \\
\hline $\mathbf{f}$ & .200 & .176 & .156 & .280 & .400 & 1 & & & & & & & & \\
\hline $\mathbf{t}$ & .157 & .143 & .227 & .116 & .159 & .179 & 1 & & & & & & & \\
\hline $\mathbf{t}$ & .180 & .163 & .256 & .140 & .186 & .200 & .750 & 1 & & & & & & \\
\hline $\mathbf{d}$ & .255 & .239 & .400 & .195 & .368 & .175 & .340 & .465 & 1 & & & & & \\
\hline $\mathbf{k}$ & .128 & .105 & .147 & .172 & .233 & .280 & .381 & .324 & .167 & 1 & & & & \\
\hline $\mathbf{k}$ & .143 & .122 & .162 & .188 & .242 & .286 & .300 & .289 & .178 & .739 & 1 & & & \\
\hline $\mathbf{g}$ & .167 & .146 & .222 & .242 & .500 & .233 & .152 & .174 & .384 & .300 & .387 & 1 & & \\
\hline $\mathbf{s}$ & .343 & .324 & .222 & .156 & .212 & .400 & .279 & .387 & .300 & .233 & .286 & .200 & 1 & \\
\hline $\mathbf{z}$ & .586 & .548 & .324 & .176 & .265 & .267 & .235 & .279 & .410 & .176 & .189 & .250 & .536 & 1 \\
\hline
\end{tabular}

Sets of Consonants (SIM $\geq .28$, DISSIM < .28)

\begin{tabular}{|c|c|c|c|}
\hline Set & Freq & Pairs & \\
\hline \multirow{2}{*}{$\begin{array}{l}\text { SET } 5 \\
\text { SIM } \\
.28-.56\end{array}$} & Low & 18 & $\begin{array}{l}\text { t s, s t, s f, f s, z d, d z, z t, t z, s d, d s, t' s, k t, b g, n m, k' f, } \\
\text { f k, z r, n d }\end{array}$ \\
\hline & High & 26 & $\begin{array}{l}\mathrm{k}^{\prime} \mathrm{t}^{\prime}, \mathrm{t}^{\prime} \mathrm{k}, \mathrm{d} \mathrm{g}, \mathrm{g} \mathrm{d}, \mathrm{d} \mathrm{b}, \mathrm{b} \mathrm{d}, \mathrm{s} \mathrm{t} \text { ', t k, g, b, m n, s k, k s, d r, r d, } \\
\mathrm{s} \mathrm{r,} \mathrm{r} \mathrm{s,} \mathrm{z} \mathrm{l,} \mathrm{l} \mathrm{z,} \mathrm{n} \mathrm{z,} \mathrm{z} \mathrm{n,} 1 \mathrm{~s}, \mathrm{~s} \text { l, k f, f k', r z, d n }\end{array}$ \\
\hline \multirow[b]{2}{*}{$\begin{array}{l}\text { SET } 6 \\
\text { DISSIM } \\
.16-.27\end{array}$} & Low & 23 & $\begin{array}{l}\text { z k, z k', z g, t' f, m z, t f, k m, s g, k' m, f d, b n, n k, t b, k b, f z, } \\
\text { z f, t n, n t, g f, f g, s k' }\end{array}$ \\
\hline & HIGH & 75 & 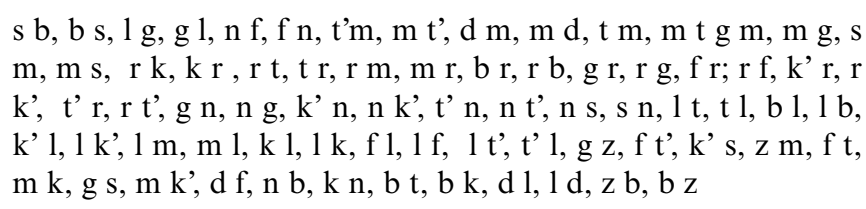 \\
\hline
\end{tabular}


Amharic error rate per set ( 0.28 cut-off)

\begin{tabular}{|l|c|c|c|c|} 
& Errors & Correct Tokens & Total Tokens & Error rate \\
\hline Set $\mathbf{1}$ & 12 & 212 & 224 & .0536 \\
\hline Set $\mathbf{2}$ & 96 & 1136 & 1232 & .0779 \\
\hline Set 3 & 34 & 190 & 224 & .1518 \\
\hline Set 4 & 1 & 279 & 280 & .0357 \\
\hline Set 4 High freq. & 2 & 166 & 168 & .0119 \\
\hline Set 5 Low freq. & 13 & 995 & 1008 & .0129 \\
\hline Set 5 High freq. & 17 & 1439 & 1456 & .0117 \\
\hline Set 6 Low freq. & 13 & 1275 & 1288 & .0101 \\
\hline Set 6 High freq. & 38 & 4162 & 4200 & .0090 \\
\hline Total & $\mathbf{2 2 6}$ & $\mathbf{9 8 5 4}$ & $\mathbf{1 0 0 8 0}$ &. $\mathbf{0 2 2 4}$ \\
\hline
\end{tabular}

Fisher's Exact tests

Similarity hypothesis

Set 5 (Low Frequency) versus Set 6 (Low Frequency) $-p=.4279$

Set 5 (High Frequency) versus Set 6 (High Frequency) $-p=.2769$

Frequency hypothesis

Set 5 (Low Frequency) versus Set 5 (High Frequency) $-p=.8525$

Set 6 (Low Frequency) versus Set 6 (High Frequency) $-p=.6195$ 


\section{SFC Rankings - Chaha}

Shared Feature Class Similarity Matrix - Chaha

(note: $r$ and $n$ have same similarity value as they are allophones)

\begin{tabular}{|l|c|c|c|c|c|c|c|c|c|c|c|c|c|}
\hline $\mathbf{C}$ & $\mathbf{r}$ & $\mathbf{n}$ & $\mathbf{m}$ & $\mathbf{b}$ & $\mathbf{f}$ & $\mathbf{t}$ & $\mathbf{t}$ & $\mathbf{d}$ & $\mathbf{k}$ & $\mathbf{k}$ & $\mathbf{g}$ & $\mathbf{s}$ & $\mathbf{z}$ \\
\hline $\mathbf{r}$ & 1 & & & & & & & & & & & & \\
\hline $\mathbf{n}$ & 1 & 1 & & & & & & & & & & & \\
\hline $\mathbf{m}$ & .282 & .282 & 1 & & & & & & & & & & \\
\hline $\mathbf{b}$ & .184 & .184 & .450 & 1 & & & & & & & & & \\
\hline $\mathbf{f}$ & .159 & .159 & .244 & .311 & 1 & & & & & & & & \\
\hline $\mathbf{t}$ & .167 & .167 & .120 & .143 & .239 & 1 & & & & & & & \\
\hline $\mathbf{t}$ & .180 & .180 & .135 & .155 & .277 & .757 & 1 & & & & & & \\
\hline $\mathbf{d}$ & .298 & .298 & .220 & .468 & .148 & .314 & .373 & 1 & & & & & \\
\hline $\mathbf{k}$ & .111 & .111 & .136 & .160 & .244 & .514 & .405 & .151 & 1 & & & & \\
\hline $\mathbf{k}$ & .128 & .128 & .152 & .173 & .227 & .405 & .476 & .164 & .767 & 1 & & & \\
\hline $\mathbf{g}$ & .205 & .205 & .262 & .564 & .174 & .157 & .170 & .524 & .233 & .302 & 1 & & \\
\hline $\mathbf{S}$ & .308 & .308 & .133 & .157 & .444 & .357 & .463 & .265 & .244 & .317 & .174 & 1 & \\
\hline $\mathbf{z}$ & .559 & .559 & .178 & .222 & .200 & .240 & .267 & .391 & .152 & .167 & .244 & .421 & 1 \\
\hline
\end{tabular}

Sets of Consonants (0.23 cut-off)

\begin{tabular}{|c|c|c|c|}
\hline Set & Freq & Pairs & \\
\hline \multirow{2}{*}{$\begin{array}{l}\text { SET } 5 \\
\text { SIM } \\
.24-.56\end{array}$} & Low & 17 & $\begin{array}{l}\mathrm{z} \text { d, z t', t z, g b, t's, s t, d z, t' z, z t, b g, s t', t s, f s, d s, k' f, } \\
\mathrm{ft}, \mathrm{m} \mathrm{g}\end{array}$ \\
\hline & HIGH & 30 & $\begin{array}{l}\mathrm{k}^{\prime} \mathrm{t}^{\prime}, \mathrm{k} \mathrm{t}, \mathrm{d} \text { b, d g, t' k', k t, b d, g d, s f, s d, f k', f k, f t', t' f, t f, } \\
\mathrm{g} \mathrm{z}, \mathrm{z} \text { g, k' s, s k', k s, s k, d r, r d, m r, r m, r s, s r, r z, z r, g m }\end{array}$ \\
\hline \multirow[b]{2}{*}{$\begin{array}{l}\text { SET } 6 \\
\text { DisSIM } \\
.11-.23\end{array}$} & Low & 14 & $\mathrm{z} \mathrm{k}^{\prime}, \mathrm{z} \mathrm{k}, \mathrm{k} \mathrm{m}, \mathrm{k}^{\prime} \mathrm{z}, \mathrm{k} \mathrm{z}, \mathrm{m} \mathrm{k}, \mathrm{b} \mathrm{z}, \mathrm{m} \mathrm{k}, \mathrm{s} \mathrm{m}, \mathrm{m} \mathrm{z}, \mathrm{f} z, \mathrm{z} \mathrm{f}, \mathrm{t} \mathrm{b}, \mathrm{b} \mathrm{t}$ \\
\hline & HIGH & 47 & $\begin{array}{l}\text { b s, d f, f g, g s, b r, d m, f n, f r, g n, g r, k' n, t' n, k' r, k r, } \\
\text { m t', m t, r t, r t', s b, fd, g f, kf, s g, r b, m d, n f, r f, n g, r g, } \\
\text { n k', n t', r k', r k, t'm, t m, t r, t' r, z b, k' m, m s, z m, k b, b } \\
\text { k, k' b, b k', t' b, b t' }\end{array}$ \\
\hline
\end{tabular}


Chaha error rate per set (.23 cut-off)

\begin{tabular}{|l|c|c|c|c|} 
& Errors & Correct Tokens & Total Tokens & Error rate \\
\hline Set 1 & 17 & 255 & 272 & .0625 \\
\hline Set 2 & 35 & 509 & 544 & .0643 \\
\hline Set 3 & 105 & 711 & 816 & .1287 \\
\hline Set 4 Low freq. & 11 & 465 & 476 & .0231 \\
\hline Set 4 High freq. & 3 & 65 & 68 & .0441 \\
\hline Set 5 Low freq. & 24 & 1132 & 1156 & .0207 \\
\hline Set 5 High freq. & 30 & 2010 & 2040 & .0147 \\
\hline Set 6 Low freq. & 7 & 945 & 952 & .0074 \\
\hline Set 6 High freq. & 35 & 3161 & 3196 & .0110 \\
\hline Total & $\mathbf{2 6 7}$ & $\mathbf{9 5 2 3}$ & $\mathbf{9 5 2 0}$ &. $\mathbf{0 2 8 0}$ \\
\hline
\end{tabular}

Fisher's Exact tests

Similarity hypothesis

Set 5 (Low Frequency) versus Set 6 (Low Frequency) $-p=.3614$

Set 5 (High Frequency) versus Set 6 (High Frequency) $-p=.2009$

Frequency hypothesis

Set 5 (Low Frequency) versus Set 5 (High Frequency) $-p=.2020$

Set 6 (Low Frequency) versus Set 6 (High Frequency) $-p=.4572$

Error rate per set (alternate 0.35 cut-off)

\begin{tabular}{|l|c|c|c|c|} 
& Errors & Correct Tokens & Total Tokens & Error rate \\
\hline Set 5 Low freq. & 13 & 599 & 612 & .0212 \\
\hline Set 5 High freq. & 12 & 736 & 748 & .0160 \\
\hline Set 6 Low freq. & 18 & 1478 & 1496 & .0120 \\
\hline Set 6 High freq. & 53 & 4435 & 4488 & .0118 \\
\hline
\end{tabular}

Fisher's Exact tests

Similarity hypothesis

Set 5 (Low Frequency) versus Set 6 (Low Frequency) $-p=.1145$

Set 5 (High Frequency) versus Set 6 (High Frequency) $-p=.3699$

Frequency hypothesis

Set 5 (Low Frequency) versus Set 5 (High Frequency) $-p=.4207$

Set 6 (Low Frequency) versus Set 6 (High Frequency) $-p=.8913$ 